Article

\title{
A Study of the Interaction of Human Smart Characteristics with Demographic Dynamics and Built Environment: The Case of Limassol, Cyprus
}

\author{
Maroula N. Alverti ${ }^{1, *}$, Kyriakos Themistocleous $^{2}$, Phaedon C. Kyriakidis ${ }^{1,2}$ and \\ Diofantos G. Hadjimitsis ${ }^{1,2}$ \\ 1 Department of Civil Engineering and Geomatics, Faculty of Engineering and Technology, Cyprus University \\ of Technology, Limassol 3036, Cyprus; phaedon.kyriakidis@cut.ac.cy (P.C.K.); \\ d.hadjimitsis@cut.ac.cy (D.G.H.) \\ 2 ERATOSTHENES Centre of Excellence, Limassol 3036, Cyprus; k.themistocleous@cut.ac.cy \\ * Correspondence: mn.alverti@edu.cut.ac.cy
}

Received: 2 January 2020; Accepted: 13 February 2020; Published: 17 February 2020

check for updates

\begin{abstract}
The smart city notion provides an integrated and systematic answer to challenges facing cities today. Smart city policy makers and technology vendors are increasingly stating their interest in human-centered smart cities. On the other hand, in many studies smart city policies bring forward a one-size-fits-all type of recommendation for all areas in question instead of location-specific ones. Based on the above considerations, this paper illustrates that smart citizen characteristics, alongside local urban challenges, are paving the way towards more effective efforts in smart city policy decision making. Our main presumption is that the development level of human-centered indicators of smart cities varies locally. The scientific objective of this paper is to find a simple, understandable link between human smart characteristics and local determinants in Limassol city, Cyprus. The data set consists of seven indicators defined as human smart characteristics and seven which determine local urban challenges consisting of demographic dynamics and built infrastructure attributes based on housing. Correlations of the 14 above indicators are examined in entirety and separately, as the study area was divided into three spatial sub-groups (high, moderate, and low coverage areas) depending on dispersed urbanization, as the main challenge of the study area. The data were obtained mainly from the most recent population census in 2011 and categorized in sub-groups by triggering CLC 2012. Analyzing the statistics using principal component analysis (PCA), we identify significant relationships between human smart city characteristics, demographic dynamics and built infrastructure attributes which can be used in local policy decision making. Spatial variations based on the dispersed urbanization are also observed regarding the above-mentioned relationships.
\end{abstract}

Keywords: human-centered smart cities; dispersed urbanization; urban challenges; local determinants; urban planning; Limassol; Cyprus

\section{Introduction}

The Smart City stands at the confluence of the spatial and technological subsystems as an answer to urban challenges in an increasingly urbanized world [1-4]. An EU report [5] estimates that around $70 \%$ of Europe's population lives in cities, with the significant percentage of this urban population living in small and medium-sized cities. Thus, the smart city concept is rapidly gaining momentum and worldwide attention as a promising response to the challenge of urban sustainability in both large and medium-sized cities [6,7].

As Thompson [8] pointed out, although "a definitive definition for smart city is lacking, in many aspects this is by no means a terrible void". The smart city concept is complex, multidimensional and 
multidisciplinary; thus, one common definition might not be applicable. However, there are numerous definitions in literature. Our preferred definition for the smart city concept is, the "[S]mart city is an effective integration of physical, digital and human systems in the built environment to deliver a sustainable, prosperous and inclusive future for its citizens" [9]. Being "smart" is not an end state, but rather can be an enabling condition that may lead to other desirable social, economic, or environmental outcomes [10].

The major challenges that European cities are facing are gaining and maintaining the competitive edge in a globally interconnected economy [11,12]; appealing to the most talented, skilled, and creative citizens; overcoming sustainability challenges and resource limitations that necessitate efficiency improvements $[9,13]$; contributing to climate stabilization by speeding up transition to low-carbon society and promoting renewable energy [14]; improving the transparency of urban management [9]; improving quality of life and dealing with multiple socio-economic challenges such as inequality, insecurity, social inclusion, unemployment, and an aging population [15]; and overall, making strides towards achieving sustainable development goals. However, despite the rise in the smart city notion in the urban planners' debate on the future of cities, the diffusion of smart initiatives in countries and regions with different needs and contextual conditions (e.g., in either developed or developing nations) makes it difficult to identify shared definitions and common current trends and challenges [16]. In this respect, the vast majority of previous studies have ignored the fact that the impact of a given dimension could vary from one location to another.

Monzon and Chourabi $[2,17]$ emphasized that nowadays cities have many different fields to work on so that they can become better places for living. Batty [18] takes an urban modeling approach to synthesize how concepts from complexity science may shape our understanding of today's cities and how cities can be designed in better ways. Zaman [19] identified critical factors and challenges for resource efficiency and management, while McGrath [20] investigated how to properly integrate ecology and urban design in smart cities contexts. These studies bring forward a one-size-fits-all type of recommendation for all areas in question instead of location-specific ones. Comprehensively exposing local city challenges allows us to better identify those areas that can fruitfully collaborate to realize the smart city vision. On the other hand, Neirotti et al. [16] emphasized that current trends and evolution patterns of any individual smart city implementation depends to a great extent on local city factors. Santana et al. [21] also pointed that each region has its specific local characteristics and the same solution is not applicable for all regions and thus should be based on each city's true needs. However, it is still unclear how and to what extent the local city's challenges affect smart city implementation. Looking at the future as a design opportunity, this paper offers an alternative perspective to the technocentric and universalist approach on smart cities through a design-driven and human-centric approach. The aim of this study is to illustrate a methodology which combines local factors (demographic and built infrastructure attributes) that euro Mediterranean medium-sized cities affect together with human smart characteristics that arise locally.

This exploratory study of what we might call a "humane-smart city dimension" aims at paving the way towards more urban challenges-oriented efforts. As a case study, we consider the Limassol Metropolitan Area (LMA), a dynamic medium-sized urban agglomeration in southern Europe which dominates the trade and economy of the extended southern Mediterranean and Middle Eastern regions, regarding its geopolitical position [22]. The investigation covers both statistical and spatial data, from the most recent population census data (2011), alongside CLC 2012 obtained by the Copernicus European Program. This article is the first step towards answering the following research questions:

RQ1 How do human smart dimensions change at different urban neighborhoods? In other words, are the dimensions global, stationary across the city's neighborhoods, or local, varying from one location to another?

RQ2 What are the local determinants that contribute to these human smart dimension changes?

In order to answer the above research questions, a set of fourteen variables were identified from the literature, seven of them (as main variables) in order to interconnect human smart city characteristics 
with urban challenges that European cities face, under the lights of the new European Cohesion Policy Agenda 2021-2027. Moreover, a set of seven supportive variables were identified for local differentiation, which consist of demographic (3) and built environment (4) attributes. In this study we examine a method for monitoring the spatial distribution of the human smart city characteristics. The remainder of this article is organized as follows. The human smart characteristics according to urban challenges in the European context are defined in Section 2. Section 3 discusses the methodology obtained and the manipulation both of statistical and spatial data. The case study area and the variable variations are presented in Section 4. Section 5 interprets the results of the statistical analysis and spatial distribution of the components obtained in the LMA. Section 6 discusses the research findings and their policy implications. Finally, Section 7 summarizes the main findings and proposes areas for further research and highlights policy implications.

\section{Defining the Human Smart Dimensions through European Context}

Addressing the topic of people as part of smart cities is critical, and traditionally has been neglected at the expense of understanding more technological and policy aspects of smart cities. If a city or community wants to become smarter, it should take the needs and problems of its customers-citizens, businesses, workforce/commuters, entrepreneurs, academia, and non-profit organizations-into account and actively engage in bottom-up thinking and co-creation to identify, develop, and implement suitable solutions. According to the European Parliament (2014), a smart city consists of not only components but also people. Securing the participation of citizens and relevant stakeholders in the smart city is therefore another success factor. As Russo [23] notices, this definition explicitly introduces the people component in the system concept of smart cities. Giffinger [12] stated that a smart city cannot exist without a smart population. Citizens are the key part for this knowledge-based urban development, because people not only receive information, but are also the driving force for its creation. According to Caragliu [7] city tends to be smart when investments in human and social capital and traditional (transport) and modern (ICT) infrastructure fuel sustainable economic growth and a high quality of life, with a wise management of natural resources, through participatory governance. Smart cities represent a conceptual urban development model based on the utilization of human, collective, and technological capital for the enhancement of development and prosperity in urban agglomerations [24]. Dameri [25] argues that citizen involvement plays a critical role in both social and technical transformations, both of which are central to the smart city. The intent of the smart city should be to offer its citizens the highest possible quality of urban life; however, in many of the smart city ideals, technology is implicitly employed as a force that relentlessly pushes the future evolution of the built environment [26]. The city's intelligence can be assessed, based on the population collective intelligence, provided a smart city is thought of as a cluster of smart people $[27,28]$.

The development of a smart city approach and its implementation in various countries has generated fruitful research results and policy guidelines. According to Anttiroiko [29], smartness can be seen both in the design of policy and its implementation. Increasing smartness would then revitalize local economies to meet the challenge of a constantly evolving local-global dialectic. To gain a relatively strong socio-economic position in an open spatial system, cities or regions have to be able to exploit their indigenous assets such as knowledge, technology, entrepreneurship, accessibility, sustainability, and culture [7,30], represented by the approach of smart cities. Thus, it is important for cities to focus on increasing the competencies and qualification of the population, emphasizing the need for a better education, social infrastructure, and promoting creativity. Smart citizens are those who generate and benefit from the city's human and social capital [4]. Thus, characteristics like having an open mind, diversity, and a deep cognitive ability are important issues for the smart city population. Other dimensions stress the role of human capital and education in urban development. Berry [31] and Glaeser [32] show, for example, that the most rapid urban growth rates have been achieved in cities where a high share of educated labor force is available. Shapiro [33] and Hollands [34] come to a 
joint conclusion that smarter cities start from the human capital side, rather than blindly believing that ICT can automatically create a smart city. Factors like the capacity of humans $[31,32]$ and the role of higher education, skills, creativity, and talent [33,35] have all emerged as the main drivers of smart urban development. "An enriching community life is the final goal, and to achieve so, it is necessary to take initiatives to solve the high levels of unemployment in cities; as well as using the demographic movements and mix of population as an opportunity for innovation, taking into consideration all citizens independently of their age, gender, culture or social condition" [17].

In this context, the proposal by the European Commission (2019), the cohesion policy agenda 2021-2027, is harmonized with the above-mentioned thinking. In this new framework, cities are perceived as engines of growth and innovation but are also faced with pressing challenges such as air pollution, unemployment, and social exclusion. The policy agenda focuses on the development of local growth strategies by urban, local, or other territorial authorities, with the continuation of 'Community-Led Local Development'. The new EU agenda 2021-2027 originated from five policy objectives: (i) a smarter Europe by promoting innovative and smart economic transformation; (ii) a greener, low-carbon Europe by promoting clean and fair energy transition, green and blue investment, circular economy, climate adaptation, and risk prevention and management; (iii) a more connected Europe by enhancing mobility and digital networks; (iv) a more social Europe delivering on the European Pillar of Social Rights and supporting quality employment, education, skills, social inclusion, and equal access to healthcare; and (v) a Europe closer to citizens, by supporting locally-led development strategies and sustainable urban development across the EU. All the above policy objectives, and (v) especially, focus on integrated territorial development targeting urban areas. These strategies tackle the economic, environmental, climate, demographic, and social challenges affecting urban areas, including urban neighborhoods, administrative units of a city, and functional urban areas. In Table 1, the human-centered smart city dimensions are presented, as identified in a literature review, with references, alongside the main trends and challenges affecting cities in the European region, under the new EU cohesion policy agenda for 2021-2027 objectives. This comparison helps to better explain the selected variables, which are defined as human smart characteristics, that are used in the statistical analysis.

Table 1. Human centered smart city variables identification.

\begin{tabular}{|c|c|c|c|c|}
\hline $\begin{array}{l}\text { EU Policy } \\
\text { Objectives }\end{array}$ & Urban Challenges & $\begin{array}{l}\text { Human Smart } \\
\text { City Dimensions }\end{array}$ & Variable Description & References \\
\hline (i), (iv) & $\begin{array}{c}\text { Improving labor force market } \\
\text { competitiveness/social innovation } \\
\text { economy }\end{array}$ & $\begin{array}{l}\text { Level of } \\
\text { Educational } \\
\text { Attainment }\end{array}$ & $\begin{array}{l}\text { Share of population with } \\
\text { University degree }\end{array}$ & {$[7,11,12,16,35-37]$} \\
\hline (i), (v) & $\begin{array}{l}\text { Managing adaptation to } \\
\text { innovation and knowledge-based } \\
\text { economies }\end{array}$ & $\begin{array}{l}\text { Creativity - } \\
\text { Innovation }\end{array}$ & $\begin{array}{l}\text { Share of employed in } \\
\text { Knowledge Intensive } \\
\text { Services (KIS) }\end{array}$ & {$[16,37-41]$} \\
\hline (ii) & $\begin{array}{l}\text { Increasing waste management } \\
\text { disposal } \\
\text { (separation/recycling/reuse) and } \\
\text { promoting circular economy }\end{array}$ & $\begin{array}{l}\text { Environmental } \\
\text { Awareness }\end{array}$ & $\begin{array}{l}\text { Proportion of waste } \\
\text { recycled }\end{array}$ & {$[16,38,42-45]$} \\
\hline (ii), (v) & $\begin{array}{l}\text { Reducing ecological footprint and } \\
\text { pressure on ecosystems. } \\
\text { Promoting renewable energy such } \\
\text { as solar, wind etc. }\end{array}$ & $\begin{array}{l}\text { Energy Transition } \\
\text { (Renewable/green } \\
\text { energy) }\end{array}$ & $\begin{array}{l}\text { Proportion of renewable } \\
\text { energy consumed }\end{array}$ & {$[2,4,16,46-48]$} \\
\hline (iii) & $\begin{array}{l}\text { Improving ICT networks and } \\
\text { access to citizens. Promoting ICT } \\
\text { connectivity }\end{array}$ & Use of ICT & $\begin{array}{l}\text { Proportion of households } \\
\text { with broadband internet } \\
\text { connection }\end{array}$ & {$[2,7,12,49]$} \\
\hline (iii) & Improving citizens digital skills & Digital Inclusion & $\begin{array}{c}\text { Share of population using } \\
\text { digital divices }\end{array}$ & {$[16,48,50,51]$} \\
\hline (iv) & $\begin{array}{l}\text { Enhancing social inclusion of } \\
\text { migrants and refugees }\end{array}$ & $\begin{array}{l}\text { Social Plurality and } \\
\text { Ethnic Diversity }\end{array}$ & $\begin{array}{l}\text { Share of population whose } \\
\text { country of birth is not } \\
\text { Cyprus }\end{array}$ & {$[11,37,38,52]$} \\
\hline
\end{tabular}




\section{Study Methodology}

\subsection{Procedure Steps}

The overall methodology is summarized into six steps and presented in Figure 1. The first three steps (steps 1-3) address the preprocessing stages, while steps 4 and 5 are focused on the statistical analysis and the spatial distribution of the extracted components accordingly. Step 6 concerns the post-processing stage of the proposed methodology including analysis results, conclusions, and policy implications.

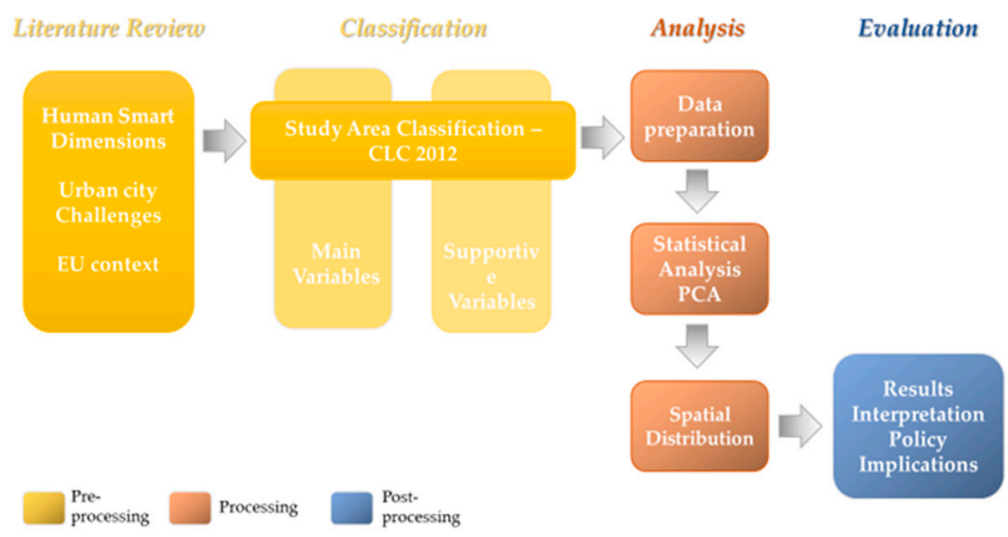

Figure 1. Methodological framework work flow.

The pre-processing procedure concerns the literature review, variables selection, and data preparation. The literature review helped identify key desirable human smart dimensions which address European city challenges under the framework of the proposed EU policy agenda (step 1). In step 2, all variables (main and supportive) that merge LMA urban character and its citizen's needs are identified. An appropriate variable must be (1) clear [53], scientifically rigorous [54], and as objective as possible [55]; (2) pertinent [56] and reliable [57]; (3) based on accurate, accessible information [58], and (4) easily applied and understandable [59]. These four criteria were applied when identifying variables for the selection process in our study. Based on the above methodology, an initial pool of 14 evaluation variables was selected. The main variables (7) concerning the human smart characteristics and their supporting factors were divided into demographic dynamics (3) and built environment attributes (4). The sources and conceptual premises of these items are summarized in Table 1. In addition, in this step the study area classification was applied in terms of its main urban challenge, the dispersed urbanization, according to the CLC class " 111 continuous urban fabric" with SL $>80 \%$. The LMA is divided in three groups given the standard variation, in high, moderate and low coverage areas (see Section 4). According to the descriptive statistics, the data set is heterogeneous, due to the diversity of the different kinds of data. Based on the descriptive statistics for each dataset, the final data structure was formulated. Before proceeding to the statistical analysis, data were checked for their existing correlations presented in a Pearson correlation coefficient matrix (step 3). As well as a correlation matrix, Kaiser-Meyer-Olkin's measure of sampling adequacy, Bartlett's test of sphericity, Measures of Sampling Adequacy (MSA) and Gronbach's alpha were calculated, to ensure that the available data are appropriate for statistical analysis. In step 4, the data obtained was analyzed using a dimension reduction algorithm called Principal Component Analysis (PCA). Mapping the spatial distribution of the extracted components of PCA, follows a spatially enabled analysis using geographical information system, in order to analyze the local effects of human smart city characteristics (step 5). This mapping takes into account factors that express the demographic structure and dynamics of the residents of the study area, as well as factors that determine the urban infrastructure in correlation with the human smart characteristics of the study area. Finally, in step 6, the overall results concerning statistical and spatial analyses are evaluated. The conclusions of the study demonstrate the different impact 
that human smart characteristics have in LMA, concerning also policy implications referred to in the proposed European Cohesion Policy Agenda 2021-2027.

\subsection{Data Source}

The main data source for the present study is the available official data of the latest population census of Cyprus conducted in 2011. The statistics and spatial data of this census are available at country, district, municipality/community, quarter, and postal code level. In several studies the postal code was chosen to be used as the smallest spatial level of analysis [60-62]. The postal code, as the smallest spatial level of analysis, can better highlight the local variations of the variables considered. Postal codes were chosen as the elementary spatial unit in this study area, as they are the minimum mapping units of population census and allow reliable comparisons with indicators derived from official statistical data sources.

The data employed in this study include both statistical and spatial data and were obtained from two different resources. Firstly, the polygons of the 136 postal codes of the study area, alongside the statistical data for population census 2011, were obtained from Cyprus Statistical Office, which can be accessed and freely downloaded from the official website (http://www.cystat.gov.cy). Data concerning household recycling on plastic bottles, metal packaging and drink cartons (PMD), paper, and glass for years 2010-2012 was obtained from Green Dot, the only licensed recycling and management system in Cyprus, from the official website http://greendot.com.cy.

\subsection{Geographical Analysis}

The geospatial data obtained from CYSTAT consists mainly of polygons in shape feature class with polygon geometry type in WGS_1984 Geographic Coordinate System. In order to analyze the local urban features of LMA, we used the CLC map of 2012 spatial data set, collected by Copernicus DEM data set, which is a Digital Surface Model (DSM) which represents the surface of the Earth including buildings, infrastructure, and vegetation. The CLC is a vector map in 1:100,000 scale, with a minimum cartographic unit of $25 \mathrm{ha}$ and a geometric accuracy better than $100 \mathrm{~m}$. It maps homogeneous landscape patterns, i.e., more than $75 \%$ of the pattern has the characteristics of a given class from the nomenclature. This map delimitates land covers through a photo-interpretation process and manual digitalization of high-resolution digital color aerial photography on the computer screen. This method is considered the best way to capture information regarding urban trends [63] and makes possible the generalization and distinction between different land uses and, also, the identification of relevant characteristics which are better distinguished by their visual form and pattern [64].

Across the CLC 3-level hierarchical classification nomenclature with 44 classes at the third and most detailed level, in this study we use the class "111 continuous urban fabric", in which the average degree of soil sealing (SL) is above $80 \%$. The variation of this CLC class demonstrates the dispersed urbanization across LMA, which is the main urban challenge of the Cypriot cities, as mentioned in the Limassol Structure Plan. In order to identify this variation, the study area was divided into three groups depending on the standard deviation of this class: high, medium, and low coverage area. The analysis of CLC 2012 and Population Census 2011 geodatabase based on PCs was performed combining the cartographic and census data sources previously described. To estimate the percentage of artificial surfaces from the CLC 2012 associated to each polygon, we overlaid the land cover map and the population census 2011 geodatabase map using the spatial join tool provided by ArcGIS (ESRI 2011, desktop release 10.4). The surface area of each defined SL land cover class was then calculated and assigned to each enumeration polygon based on the ArcGIS 'intersect' tool. The land cover composition in the investigated study area was calculated as the percent surface area of each class over the total surface area. A total of 136 postal codes were considered with an average area of $1705 \mathrm{Km}^{2}$ each with a maximum of $25.060 \mathrm{~km}^{2}$ and minimum of $0.1287 \mathrm{~km}^{2}$. Larger polygons are, normally, concentrated in the urban expansions of the city (east and west mainly), while smaller ones are found in the most 
central areas. As for the population, each one of the 136 postal codes consist of a population ranging from 31 to 4405 residents, with a standard deviation of 1520.73 .

\subsection{Statistical Analysis}

The statistical data used in this study are divided into main and supportive variables. The main variables (human smart characteristics) were extracted from the literature and based on the urban challenges that European cities face. They are analyzed in Section 2 (Table 1) and consist of human smart data: individual computer use, household's internet use and solar and photovoltaics use, population enumerated with university education (first degree and master's or doctorate degree) and employment in Knowledge Intensive Services (KIS). The supportive variables identify the local determinants and specify the local variation. They consist of demographic dynamics such as age structure, household size, family nuclei, population by the country of birth, and built infrastructure attributes such as single houses as building type, average monthly housing rent, rented housing, and average dwelling size. Principal component analysis was performed on 14 variables (main and supportive) for the three groups based on area coverage (high, medium, low coverage areas) and for the whole study area, in order to identify local variations between human smart characteristics, demographic dynamics, and built infrastructure of LMA.

Principal component analysis is a multivariate statistical procedure used to synthesize multiple variables by transforming the original variables into a new set of orthogonal variables in such a way that variation is emphasized and strong patterns become noticeable [65]. These new sets of variables are fewer than or equal to the number of original variables and have been transformed so that a small number of principal components will account for a large part of the original data variation [66]. PCA serves as an effective tool for synthesizing multidimensional data and creating new indices, which can be used for ranking. PCA aims to extract the maximum variance from a data set with each component. "The first principal component is the linear combination of observed variables that maximally separate subjects by maximising the variance of their component scores" [67]. The second component is computed from the residual correlations. It is the linear combination of observed variables that extracts maximum variability. This variability is uncorrelated to the first component. The subsequent components also extract maximum variability from the residual correlations and are independent from all the other components. The extracted components represent most of the variance of the original data set and can be used in further analysis. The aim of the study is therefore based on the selected initial variables, to create new components that will reflect the impact of human smart characteristics on the urban expansion of Limassol city based on demographic, social, and economic features.

In mathematical terms, PCA can be explained as follows.

From a set of variables, $\mathrm{X}_{1}, \mathrm{X}_{2}$ to $\mathrm{X}_{\mathrm{m}}$, the principal components $\mathrm{PC}_{1}$ to $\mathrm{PC}_{\mathrm{m}}$ are extracted:

$$
\begin{gathered}
\mathrm{PC}_{1}=\mathrm{a}_{11} \mathrm{X}_{1}+\mathrm{a}_{12} \mathrm{X}_{2}+\ldots \ldots+\mathrm{a}_{1 \mathrm{n}} \mathrm{X}_{\mathrm{n}} \\
\ldots \ldots \\
\ldots \ldots \\
\ldots \ldots \\
\mathrm{PC}_{\mathrm{m}}=\mathrm{a}_{\mathrm{m} 1} \mathrm{X}_{1}+\mathrm{a}_{\mathrm{m} 2} \mathrm{X}_{2}+\ldots \ldots+\mathrm{a}_{\mathrm{mn}} \mathrm{X}_{\mathrm{n}}
\end{gathered}
$$

where $a_{m n}$ represents the weight for the $m_{\text {th }}$ principal component and the $n_{\text {th }}$ variable. The weights of each principal component are given by the eigenvectors of the correlation matrix or the co-variance matrix. The variance for each principal component is given by the eigenvalue of the corresponding eigenvector. For the statistical analysis, the statistical package SPSS for WINDOWS (IBM Corp. Released 2017. IBM SPSS Statistics for Windows, Version 25.0. Armonk, NY: IBM Corp.) was used. 


\section{Case Study Area}

The investigated area coincides with the Limassol Metropolitan Area (LMA), the largest agglomeration in Cyprus and the southernmost of the European Union [68]. It is subdivided in 15 municipalities and 5 communes including the Municipality of Limassol, the largest agglomeration in Cyprus and the southernmost of the European Union (Figure 2). It is a coastal area of $231.40 \mathrm{~km}^{2}$, accommodating 208,980 inhabitants (Cystat, 2011), consisting of the $89.58 \%$ of the total district population.

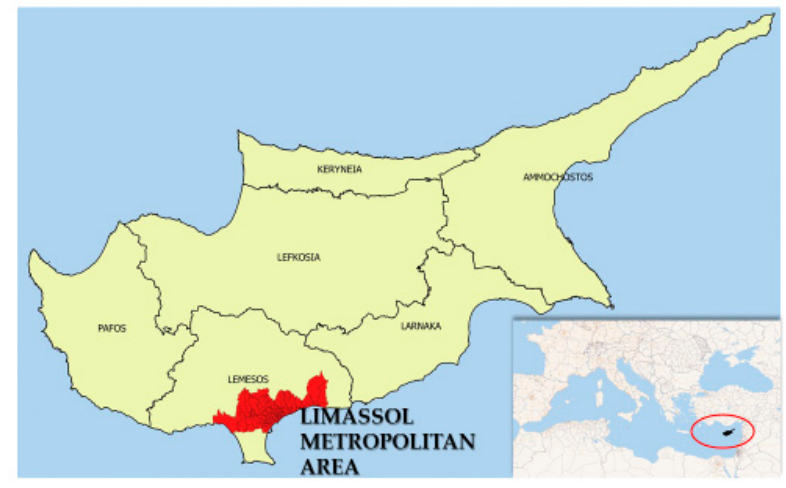

Figure 2. Cyprus in the Mediterranean basin and the Limassol Metropolitan Area (LMA) study area.

The study area is the southernmost European urban agglomeration, which represents a Mediterranean example of semi-compact urban agglomeration evolving towards a dispersed urban form. Limassol occupies the southern point of Cyprus and is the largest port in the country, home of the third largest merchant navy in Europe and a highly diverse city. Therefore, one could claim that Limassol qualifies as a major European city, as a modern city that accommodates people of diverse origins and cultures, and as location where a variety of international financial services exist, which dominate the trade and economy of the extended southern Mediterranean and Middle Eastern regions [22]. After the 1974 Turkish invasion in Cyprus, Limassol was the main port entrance of the country and one of the major Mediterranean marine hubs and became one of the famous tourist destinations in Cyprus. Limassol District, given its special characteristics, faces greater urban population pressures compared with the total of Cyprus, during the last decade.

Analyzing CLC 2012, the LMA area consists of $42.70 \%$ of forests and wetlands, $24.73 \%$ of agricultural land, and $32.57 \%$ of artificial land (Figure 3). Almost half (48.19\%) of the total artificial land $\left(75.35 \mathrm{~km}^{2}\right)$ is covered by continuous and discontinuous urban fabric including housing estates and residential buildings. The high-density urbanized area (continuous urban fabric with SL $>80 \%$ ) consists of $13.61 \mathrm{~km}^{2}\left(18.06 \%\right.$ ), and the dense urban fabric (with SL 50-80\%) consists of $11.53 \mathrm{~km}^{2}$ $(15.31 \%)$ of the artificial land of LMA. This demonstrates that the densely populated area is quite limited, and the urban areas are quite scattered; thus, the main characteristic is the urban sprawl. The Limassol Structure Plan 2011 [69], which demonstrates the government strategic planning process for the area, mentioned that "the fragmentation of land ownership has been an essential obstacle to the design and implementation of unified and rationally organized urban development policies. The lack of these mechanisms allowed the rapid development of the 1980s to occur occasionally having as result the urban sprawl. Unplanned dispersal of residential development with intermediate land gaps of significant scale and excessive number of undeveloped plots makes it uneconomic to provide infrastructure, services and facilities and detracts from the social content of development". 


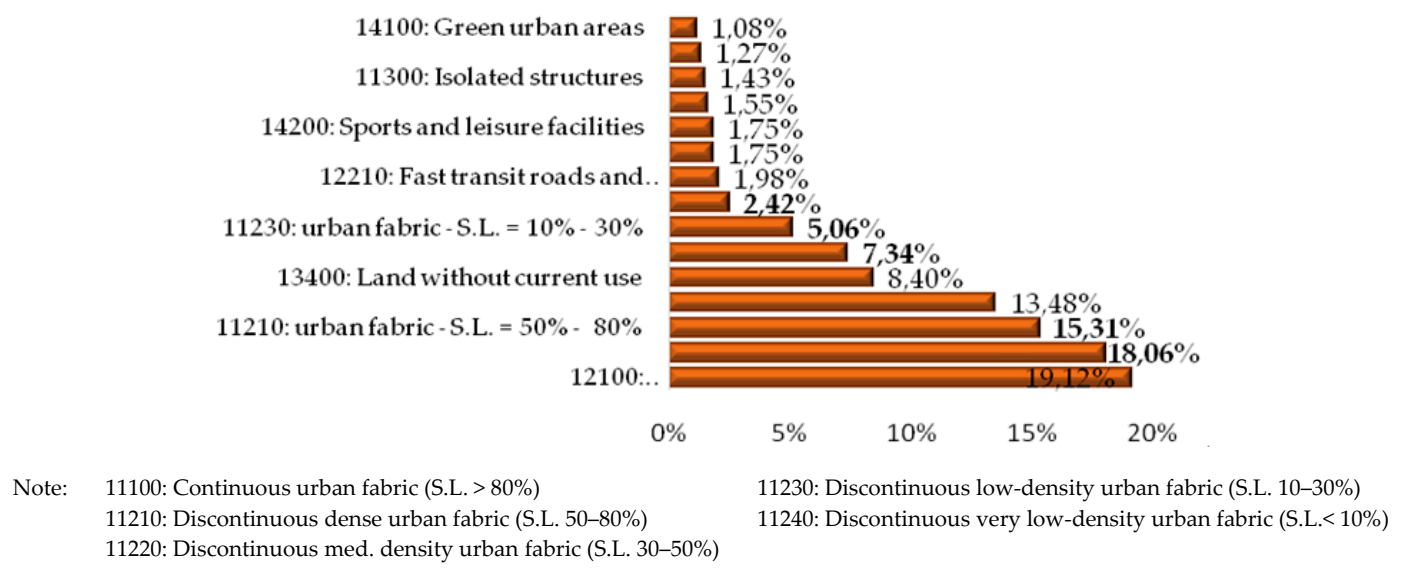

Figure 3. Corine Land Cover 2012, proportion of artificial land uses in LMA.

For the purposes of this research and to better explore the social and demographic components of the anthropomorphic environment in the shaping of human smart characteristics, in the light of the existing dispersed urbanization, the study area was divided into three groups depending on the concentrations of the continuous urban fabric index (SL > 80\%) explored using CLC 2012, in which buildings, roads, and artificially surfaced area cover almost all the ground; non-linear areas of vegetation and bare soil are exceptional. The first group contains areas having continuous urban fabric coverage of more than $49 \%$ (double standard deviation: $24.518 \%$ ) of its total surface, mentioned as high coverage areas. The second group contains areas with continuous urban fabric in the range from $49 \%$ to $12.25 \%$, mentioned as medium coverage areas. Finally, the third group contains areas with continuous urban fabric of less than $12.25 \%$ and mentioned as low coverage areas.

In more detail, the local characteristics of the LMA groups (Figure 4) are: Group_A (high coverage area): It concerns the original nucleus of the city that hosts most of the commercial uses. Of the total area, $52.41 \%$ is covered by SL $>80 \%$ and $14.40 \%$ by SL $50-80 \%$. The area's average population density is well above the Cyprus average (1055 residents $/ \mathrm{km}^{2}$ ) and reaches 5907.98 residents $/ \mathrm{km}^{2}$. The central area of the city has a high percentage (41.07\%) of residents aged over 45 years old, with $15.71 \%$ of the population aged over 65 years old. The housing stock, as expected, is old with half of the houses built before 1980. The usual habitation is in apartment blocks $(49.80 \%)$ and the average house size is $120.2 \mathrm{~m}^{2}$, corresponding to $45.57 \mathrm{~m}^{2}$ of house per inhabitant. More than half of the dwellings $(51.67 \%)$ are privately owned; however, this is the lowest owner-occupancy rate in the study area, having relatively low average monthly rent. Group_B (medium coverage area): It represents the first urban expansion of the city. Of the total area, $16.91 \%$ is covered by SL $>80 \%$ and $17.75 \%$ is covered by SL $50-80 \%$. The average population density is 2758.07 residents $/ \mathrm{km}^{2}$, recording a strong percentage of residents $(35.85 \%)$ above 45 years old and a medium concentration of $65+(11.11 \%)$. The housing stock is younger than GROUP_A with the $30.55 \%$ of houses built the last decade (2001-2011). In GROUP_B, apartments are the most common accommodation option (41.37\%), followed by single houses $(32.51 \%)$. The average house size is $135.15 \mathrm{~m}^{2}$, or $46.29 \mathrm{~m}^{2}$ of housing per inhabitant. Group_C (low coverage area): The modern extension of the urban fabric of the city. Only $1.16 \%$ of the area is covered by SL > $80 \%$ and $3.27 \%$ by SL $50-80 \%$. The average population density is low, 403.73 residents $/ \mathrm{km}^{2}$, showing characteristics referring to rural areas. The percentage of population over 45 is $31.42 \%$ and $65+$ is the lowest $(8.37 \%)$ of all other areas, while, remarkably, the concentration of residents under 45 years old is $68.58 \%$. The housing stock is the newest in all the study area with almost half of the houses $(48.16 \%)$ built in the last decade. Habitation in single houses $(61.67 \%)$ is the highest in the study area. The average house size is the highest in the study area $\left(166.09 \mathrm{~m}^{2}\right), 50.88 \mathrm{~m}^{2}$ per inhabitant. Most of the houses are single-family homes (50.99\%). The ownership rate is the highest (68.34\%) of the study area and the average monthly rent is $574.18 €$. 


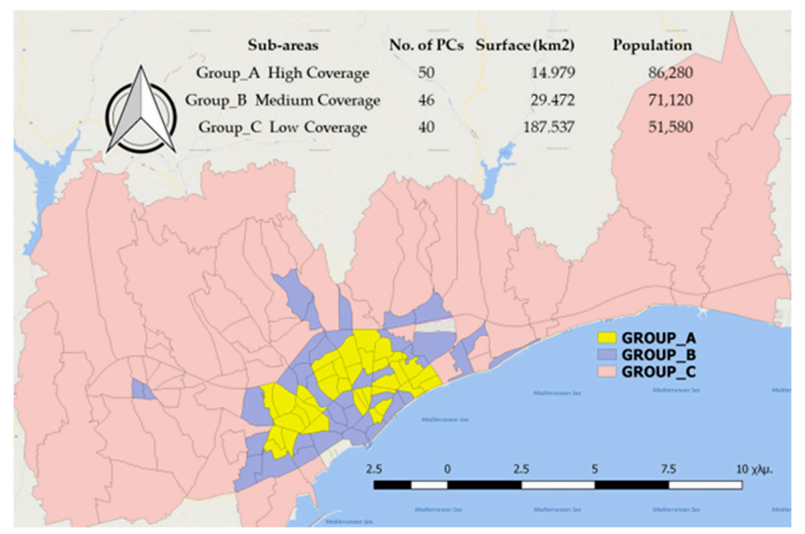

Figure 4. Study area groups.

Table 2 demonstrates the variables' names and description, in addition to descriptive statistics used in the study, for all LMA as well as in the single identified above groups.

Table 2. Variable's description by categories and descriptive statistics.

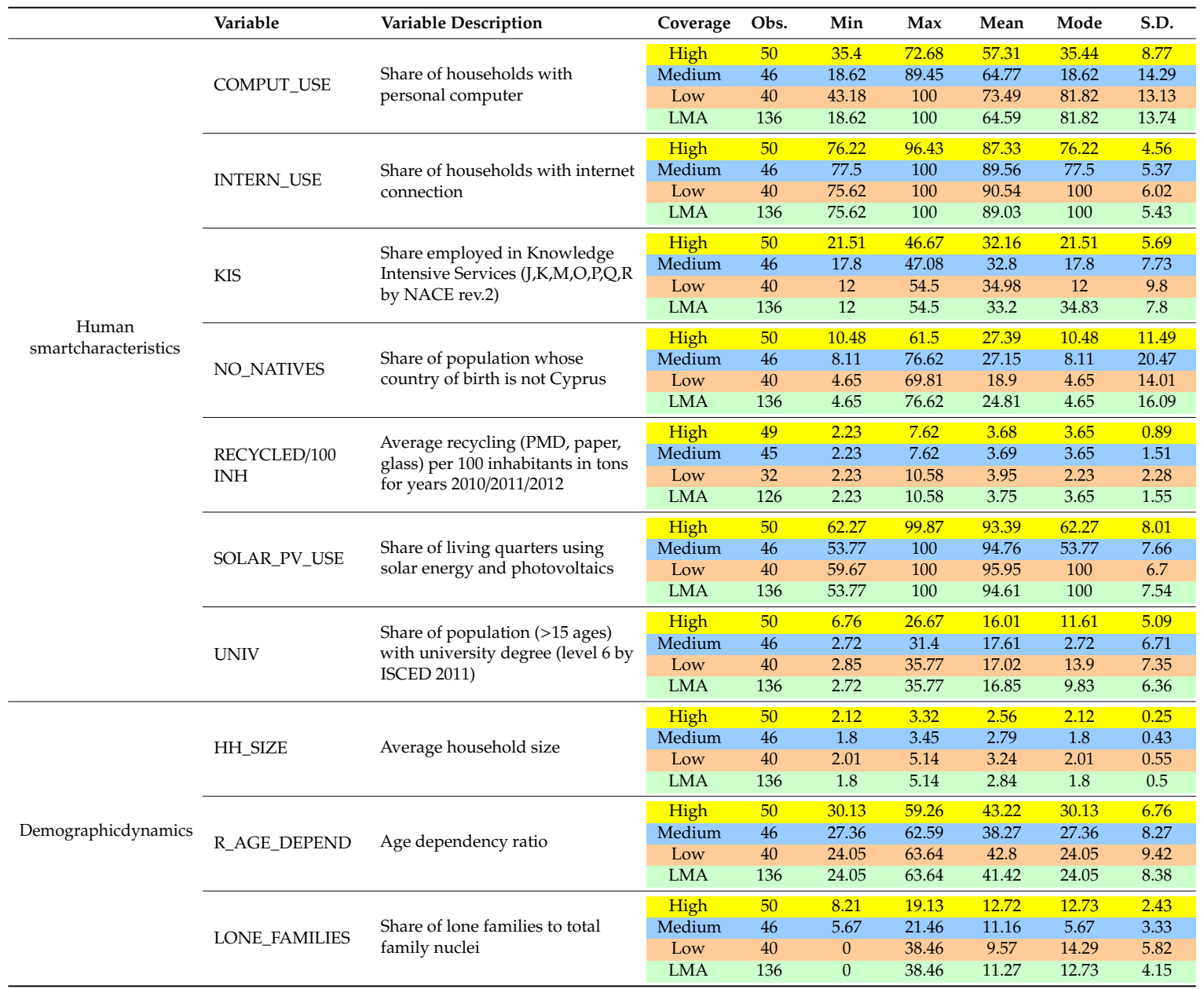


Table 2. Cont

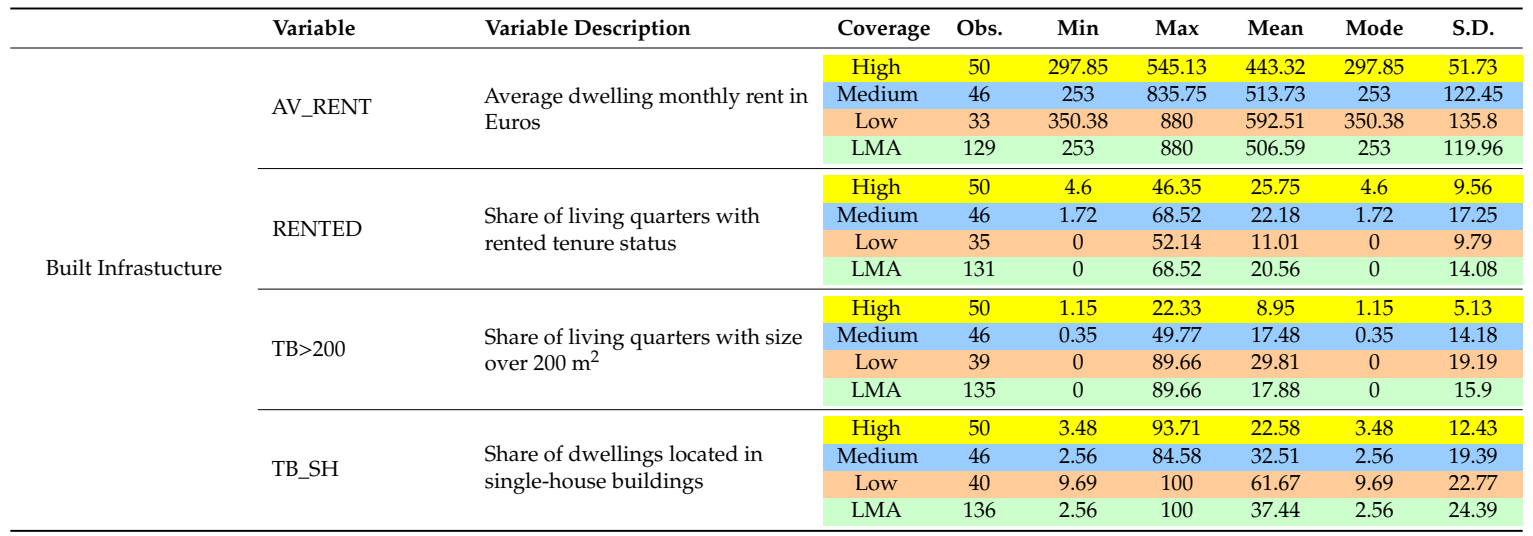

The main variables (7) are the human smart city dimensions as determined by literature, in relation to urban challenges that LMA faces and in line with recent policy objectives set up by the European Commission. These are educational attainment, employment in Knowledge Intensive Services (KIS) (J,K,M,O,P,Q,R by NACE rev.2), household recycling, household use of solar energy, households with internet connection, population computer use, and proportion of population with citizenship other than Cypriot. Furthermore, a set of supportive variables are depicted highlighting LMA local characteristics, in terms of demographic dynamics: average household size, age dependency ratio, share of lone families and built environment attributes, average monthly rent, share of rented houses, share of houses with size over $200 \mathrm{~m}^{2}$, share of single houses.

\subsection{Main Variables Descrpition}

Educational attainment: The average increase in the number of tertiary education graduates in the study area is $77.82 \%$, for the period 2001-2011, while for the same period the percentage of residents holding a $\mathrm{PhD}$ increased by $60 \%$. This was also helped by the establishment of the Cyprus University of Technology in 2007. The indicator has strong correlations with employees in KIS, computer use, rented apartments, and residential uses $>200 \mathrm{~m}^{2}$, while negative correlation occurs with non-native inhabitants. As we move away from the center, the concentration of educated citizens rises. High concentrations ( $>25 \%$ ) are recorded in the east and south (Figure $5 \mathrm{~g}$ ).

Employment in KIS: Employment in Knowledge Intensive Services (KIS) and more generally in the creative industry is an indicator that contributes to the shaping of the smart city. KIS refers to the following sectors of economic activity, based on NACE rev.2: publishing; programming; broadcasting; telecommunications; information services; financial and insurance; engineering; scientific research; advertising; security and investigation; public administration; education; human health; and arts, entertainment and recreation. The PC_KIS indicator shows in all sub-areas positive associations with computer use, tertiary education, average rent, and houses larger than $200 \mathrm{~m}^{2}$ negative associations with non-native residents. Strong concentrations (over $40 \%$ ) of PC_KIS are observed in the northern areas, i.e., the new expansions of the city (Figure $5 c$ ).

Recycling: For the purposes of the present study, data have been reduced to postal codes; thus, there are no significant spatial variations. The correlation analysis shows that the indicator performs strong positive correlations with the percentage of non-native residents and the percentage of rented dwellings, in all groups. Low concentrations are observed at the east and west of the study area, while high rates are observed in the areas where the tourist industry is strong (Figure 5e).

Solar Energy Use: The use of household solar energy (for water heating only) shows, in all regions, a strong positive correlation with household size and single house rate and a strong negative correlation with non-Cypriot residents and rented housing. The installation of solar systems indicates high concentration of native inhabitants with large families residing in privately-owned detached houses. 
The wider use of renewable energy sources, like heating of dwelling and water and photovoltaics (except for solar water heaters) for home use, is low compared to other southern European countries, due to the high installation costs and the climatic conditions of the area. In terms of spatial distribution, the lowest percentages (53-62\%) occur along the coastal zone (to Parekklisia), while the highest (over $97.3 \%$ ) occur in areas away from the center, which have been developed over the last decade (Figure $5 \mathrm{f}$ ).

Internet Use: Internet use in households is high ( $>75.6 \%)$ across the study area. Internet use is unmatched between the three sub-areas. In Group_A it shows a negative correlation $(-0.393)$ with the rented dwellings. In Group_B and in Group_C it shows positive correlation with the variables PC_KIS, PC_UNIV, AV_RENT and houses over $200 \mathrm{~m}^{2}$. Lower rates of use $(<80 \%)$ are observed in the southern and western areas (Figure $5 b$ ).

Computer Use: Unlike the above indicator, computer use in households has a strong correlation with KIS and high education, rented houses and houses over $200 \mathrm{~m}^{2}$. On the other hand, it shows a strong negative correlation with the age dependency index and single parent families (Figure 5a).
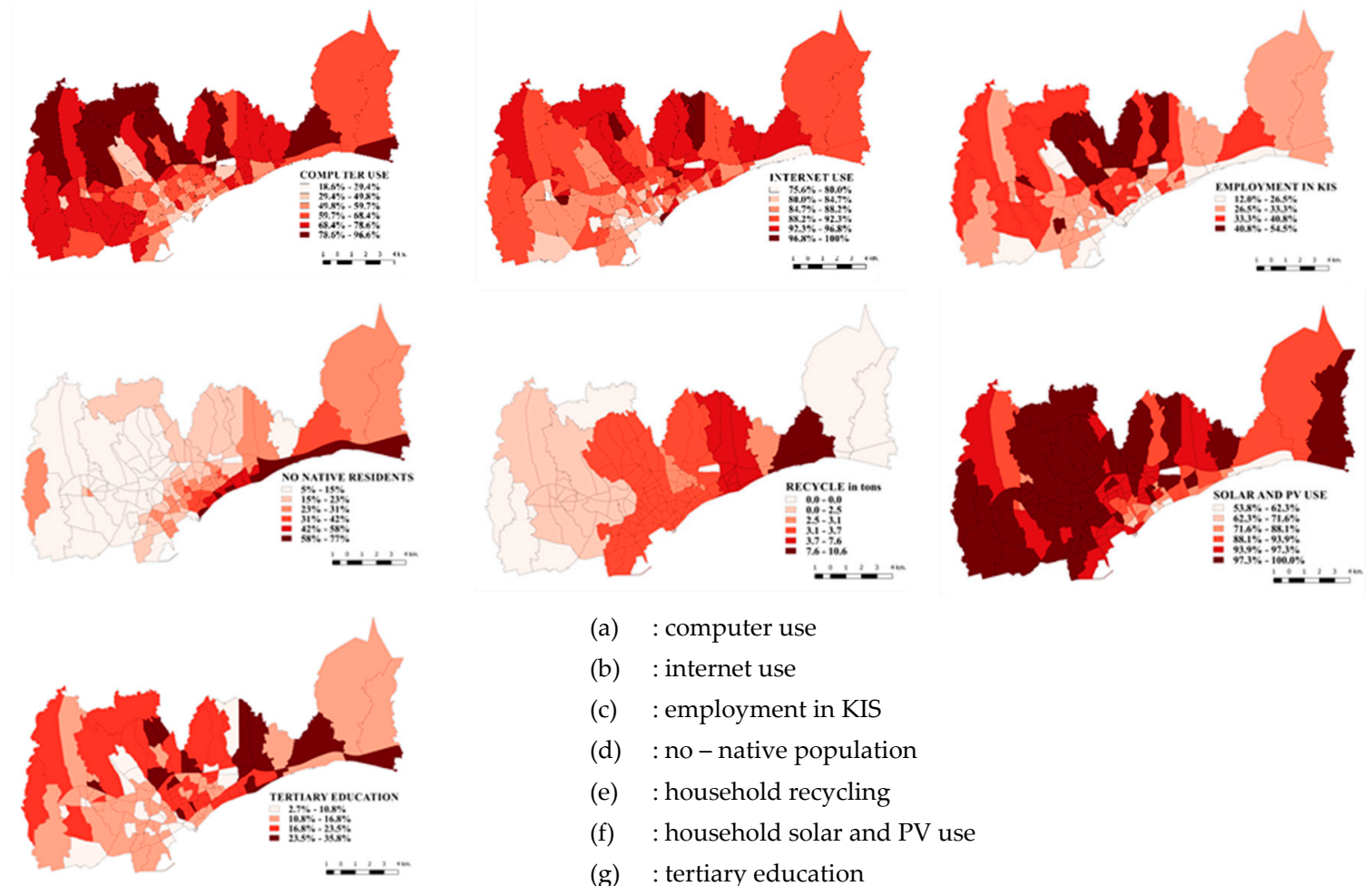

(a) : computer use

(b) : internet use

(c) : employment in KIS

(d) : no - native population

(e) : household recycling

(f) : household solar and PV use

(g) : tertiary education

Figure 5. Spatial distribution of human smart characteristics (main variables).

Migration: The population with a citizenship other than the Cypriot presents several peculiarities compared to the other southern European countries. EU nationals (representing 11.03\% of the total population), mostly from Great Britain, Romania, Greece, and Bulgaria, are mainly in productive ages (20-45 years old), except the $32.47 \%$ of British citizens that are over 60 years old. Regarding employment, $65 \%$ are employed as service, sales, craft, and related trades workers and elementary occupations in construction, retail, and accommodation/food service activities (Figure 5d). Non-EU nationals (representing $8.6 \%$ of the total population, of which $64.62 \%$ are women) come mostly from Russia and other former Soviet Union countries. Of the non-EU nationals, $26.1 \%$ are younger than 24 years. Other countries of origin are the Philippines, Vietnam, and Sri Lanka, of which $86 \%$ are between 25 and 50 years old. They are employed in elementary occupations with $74 \%$ working as household employees. The study area shows the highest rate $(21.92 \%)$ of highly educated population (tertiary attainment) with non-EU citizenship among the rest of country. The indicator used in the study refers to the whole non-native population. Larger concentrations $(>58 \%)$ are observed along 
the coastal zone, as well as in the east and north of the study area, while lower concentrations $(<15 \%)$ are observed in western regions (with lower rents) where there is no access to the sea because of the port's location. In general, as we move away from the center, the concentration of non-native inhabitants increases.

\subsection{Supportive Variables Description}

Demographic Dynamics: The key demographic feature in Cyprus and specifically in the study area is the continuous population growth over the last two decades. According to CYSTAT, the population growth of the study area in 2001-2011 was $19.73 \%$, compared to $13.20 \%$ in the previous decade (1992-2001), a total increase of 35.5\% over the last 20 years. This steady increase in population is mainly due to the natural population change and the increase in migration flows over the last decade. The steady increase in life expectancy has contributed to a decrease in the proportion of $0-14$-year-old to $15.88 \%$ in 2011 , from $21.29 \%$ in 2001 . The indicator reflecting this momentum is the age-dependency ratio, giving the number of dependent population (under 14 and over 65 ages) divided by active population ages (aged 15 to 64)*100 and expressing the number of children and the elderly corresponding to each potentially working person. The higher rate means that the number of dependents is growing faster than the number who are economically active. The study area with an average population of 40.04 years is well below the EU-28 average (49.9) reflecting the dynamics in the structure of the Cypriot population as well as the contribution of non-native residents settled in the area to find work who are in productive age. Another indicator that explains the social elements of the anthropomorphic environment is the average household size. In Cyprus and in most southern European countries, the traditional family core is maintained [70] where children continue to live with their parents after their studies (a shift in household structures away from extended families living under the same roof). Although the average household size has shrunk in recent decades in the study area, from 3.06 in 2001 to 2.89 in 2011, it stands well above the EU-27 average of 2.40.

The steady decline in household size is due to the decline in birth rates and the fact that some young people are separated from their families, even if the inclusion of an assistant at home increases the size of the household (Cystat, Demographic Report 2017). In the study area higher household size rates are noticed in areas with native population, with high rates of population aged 25-64 years (economically active) and modern housing stock. The reason for the decline of household size is that over the last twenty years there have been more 'nuclear' families, single-parent families, and single people. Household size shows the lowest rates in the high coverage area (Group_A), normally as high percentages of lone families are also observed (Figure 6a). The age dependency ratio, for the same area, shows a low to medium range due to the mixed presence of older residents in the area, along with some younger family members (Figure $6 \mathrm{~b}$ ). In the case of medium coverage area (Group_B), household size reaches its highest level as we move towards the first expansion zone of the city center. In this area, lower rates of lone families are noticed, as well as low rates of age dependency. However, with regard to age dependence, high rates are noticed especially in areas close to Group_A. The lone family rates, in the medium coverage area, are generally low and, in some cases, become higher as we move closer to Group_A (Figure 6c). Finally, in the case of the low coverage area (Group_C), household size shows the highest scores and lone families record their lowest rates. Age dependency seems to be higher in newly developed areas over the highway, in areas that show considerably low rates for lone families, mainly because of the concentration of "traditional" family nucleuses. 

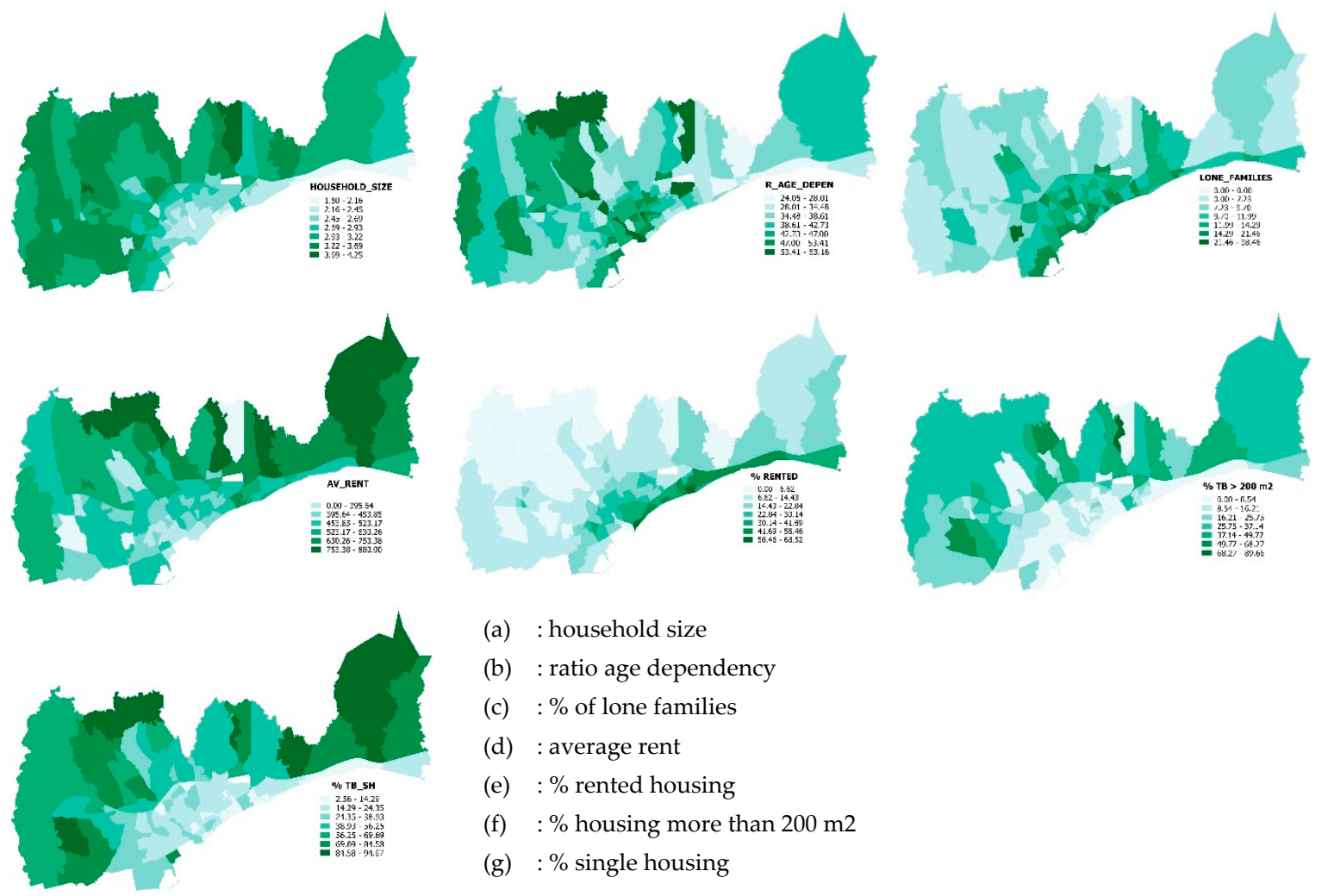
(a) : household size
(b) : ratio age dependency
(c) : \% of lone families
(d) : average rent
(e) : \% rented housing
(f) : \% housing more than $200 \mathrm{~m} 2$
(g) :\% single housing

Figure 6. Spatial distribution of local determinants (supportive variables).

Built Environment Infrastructure: Concerning the housing building type, single houses represent $40.12 \%$, apartment blocks $28.66 \%$, and semidetached or duplex houses $13.9 \%$ of the total housing stock in 2011. A significant increase was recorded in apartments during the last two decades, a $52.8 \%$ increase in the decade 1992-2001 and a 105.8\% increase in the decade 2001-2011, mainly because of the increased in-migration flows. Although privately-owned housing has a dominant role in land ownership in Mediterranean cities [70,71], home ownership has remained stable over the last 20 years with $65.3 \%$. On the other hand, the rented houses rate, due to the demand in the area, increased (from $18.3 \%$ in 2001 to $21.2 \%$ in 2011 ). However, the available houses for rent do not cover the increased demand in the study area, resulting in a substantial increase of the average rent, from $295.14 €(2001)$ to $506.6 €$ (2011) (CYSTAT, 2011). Social and demographic conditions also affect the housing size. The reduction in household size and the increase in migration result in a reduction in housing $>200 \mathrm{~m}^{2}$, from $20.2 \%$ in 2001 to $15.2 \%$ in 2011 . The above changes occurring in the built urban environment of the study area and resulting in changes in housing prices can be linked to macroeconomic developments not only at the indigenous but also at the international level [72]. Average rent is lower in the high coverage area (Group_A), normally as low percentages of large dwellings ( $\left.>200 \mathrm{~m}^{2}\right)$, old constructions, and single houses are also observed (Figure $6 \mathrm{~d}$ ). The rented houses rates, for the same area, show a low to medium range since the area is mostly occupied by indigenous inhabitants and elderly owners (Figure 6e). In the case of the medium coverage area (Group_B), average rent is getting higher as we move towards the first expansion zone of the city center. In this area, higher rates of large dwellings (Figure 6f) are observed, together with higher rates of single houses (Figure 6g). However, regarding the rented house figures, high values are observed especially in areas with sea views (Figure 6e). Finally, in the case of the low coverage area (Group_C) average rent is getting higher as well as large dwellings rates and single houses rates. The rented houses percentages are getting higher in newly developed areas along the eastern coastal zone in areas that show considerably low rates for large dwellings and single houses, mainly because of the concentration of non-native inhabitants and tourism activities. Finally, regarding the overall spatial distribution of household size and large dwellings rates, a similar 
spatial behavior may be noticed, given the concentration of high rates over the highway in both cases, as well as the concentration of low rates under the highway and along the eastern coastal zone.

\section{Results}

Various summary statistics including the mean, median, standard deviation, and correlation matrix of all 14 variables for the 136 selected postal codes of the study area were calculated. Variables derived from social sciences are usually influenced by the presence of outliers and these must therefore be taken care of. Variables containing outliers were identified as those having a distribution with absolute skewness greater or less than one [72,73]. Boxplots and histograms were plotted for each variable to ensure the data normality.

\subsection{Correlations}

Principal component analysis is based on the diagonalization of the correlation matrix. The observation of that matrix is useful because it can point out associations between variables that can show the global coherence of the data set and will evidence the participation of the individual parameters in several influence factors. Table 3 shows the correlation matrix of the variables. The computer use variable shows a strong positive relation with average rent (0.74) and large dwellings (0.75) across LMA. In detail, regarding average rent the variable computer use shows an even stronger relationship in high coverage areas (0.81). Furthermore, computer use shows a strong positive relation in medium coverage areas with KIS (0.71). On the other hand, KIS has a strong positive relation with large dwellings mainly in the medium coverage area. The non-native variable shows a strong positive relationship with rented house across LMA (0.89), which remains equally strong across the three different sub-areas with rates between 0.87 and 0.93 . Non-natives also have a strong relationship with recycling, especially in the low coverage area (0.84). However, non-natives have a clear negative correlation with solar use (-0.73) and household size $(-0.73$ to -0.78$)$, mainly in high and medium coverage areas. This is mostly because non-natives tend to live in rented dwellings and the household size is low. Recycling shows a strong positive correlation with rented dwellings (0.74) in medium coverage areas. The high education variable shows a strong positive relationship with average rent in high coverage area (0.71) and medium coverage area (0.76). The household size variable shows a strong negative relationship with rented housing across all LMA in all three sub-areas with values ranging from -0.72 to -0.75 . A strong negative correlation is also shown with lone families in medium coverage areas. Moreover, household size shows a strong positive relation with single housing across all LMA (0.74) and especially in medium coverage area in which it also shows a strong positive relationship with large dwellings (0.73). Finally, the average rent variable shows a strong positive relationship with large dwellings in LMA (0.76).

\subsection{Results of PCA Evaluation Factors}

A Principal Component Analysis (PCA) with varimax rotation was used to identify the underlying dimensions of human smart characteristics. The identification of factors and elimination of variables were based on the criteria suggested by Hair [74]: (a) factor loading equal to or greater than 0.30 , (b) eigen values equal to or greater than 1.0. According to the results of PCA, three variables in total with factor loading less than 0.5 were removed from Group_A (internet use and lone families) and Group_B (recycle/100 inhabitants). The values (from 0.624 to 0.766 ) of the KMO measure of sampling adequately indicate the appropriateness of applying factor analysis in this study. Bartlett's test of sphericity values were from 454.73 to 1721.81 at $p=0.001$ significance level, which showed that a significant correlation existed among at least some of the variables. As shown in Table 4, three main components accounted for between $74 \%$ and $78.5 \%$ of the total variance. The reliability for the items in each group, as assessed by Cronbach's alpha coefficients, was greater than 0.6, meeting the criterion suggested by Hair [74]. 
Table 3. Correlation coefficient matrix.

\begin{tabular}{|c|c|c|c|c|c|c|c|c|c|c|c|c|c|c|c|c|}
\hline & & & 1 & 2 & 3 & 4 & 5 & 6 & 7 & 8 & 9 & 10 & 11 & 12 & 13 & 14 \\
\hline \multirow{4}{*}{1} & \multirow{4}{*}{ COMPUT_USE } & High & 1 & $0.347^{*}$ & $0.544^{* *}$ & -0.024 & 0.27 & 0.116 & $0.661^{* *}$ & $0.295^{*}$ & $-0.487^{* *}$ & $-0.356^{*}$ & $0.806^{* *}$ & -0.019 & $0.556^{* *}$ & $-0.338^{*}$ \\
\hline & & Medium & 1 & $0.338^{*}$ & $0.709 * *$ & -0.123 & 0.018 & 0.15 & $0.662 * *$ & $0.531^{* *}$ & $-0.562 * *$ & $-0.614 * *$ & $0.680^{* *}$ & -0.125 & $0.748^{* *}$ & 0.253 \\
\hline & & Low & 1 & $0.663^{* *}$ & $0.663^{* *}$ & -0.026 & -0.079 & 0.069 & $0.650^{* *}$ & $0.544^{* *}$ & -0.231 & -0.205 & $0.632 * *$ & -0.175 & 0.699 ** & 0.075 \\
\hline & & LMA & 1 & $0.502 * *$ & 0.635 ** & -0.166 & 0.047 & 0.164 & 0.603 ** & $0.622 * *$ & $-0.367 * *$ & $-0.445^{* *}$ & $0.742 * *$ & -0.287 ** & $0.751 * *$ & $0.358^{* *}$ \\
\hline \multirow{4}{*}{2} & \multirow{4}{*}{ INTERN_USE } & High & & 1 & $0.358^{*}$ & -0.166 & 0.26 & $0.429^{* *}$ & 0.272 & 0.261 & -0.211 & -0.105 & $0.526^{* *}$ & -0.232 & $0.441^{* *}$ & -0.024 \\
\hline & & Medium & & 1 & 0.403 ** & 0.058 & 0.025 & 0.209 & $0.396^{* *}$ & 0.152 & $-0.327 *$ & -0.253 & $0.408 * *$ & 0.06 & $0.376^{*}$ & 0.094 \\
\hline & & Low & & 1 & $0.640^{* *}$ & -0.164 & -0.022 & $0.340^{*}$ & 0.524 ** & $0.607^{* *}$ & 0.088 & $-0.534^{* *}$ & $0.668 * *$ & -0.454 ** & $0.563 * *$ & 0.286 \\
\hline & & LMA & & 1 & $0.502 * *$ & -0.102 & 0.06 & 0.340 ** & $0.419^{* *}$ & 0.426 ** & -0.15 & $-0.400^{* *}$ & $0.541^{* *}$ & -0.214 * & $0.486 * *$ & $0.252^{* *}$ \\
\hline \multirow{4}{*}{3} & \multirow{4}{*}{ KIS } & High & & & 1 & $-0.304^{*}$ & 0.006 & 0.274 & $0.610^{* *}$ & 0.09 & 0.155 & -0.185 & $0.509^{* *}$ & -0.24 & $0.531^{* *}$ & -0.038 \\
\hline & & Medium & & & 1 & $-0.483 * *$ & -0.18 & 0.324 * & $0.507 * *$ & $0.624 * *$ & -0.155 & $-0.656 * *$ & $0.491 * *$ & $-0.444^{* *}$ & $0.813 * *$ & 0.354 * \\
\hline & & Low & & & 1 & -0.273 & -0.168 & 0.253 & $0.508 * *$ & 0.453 ** & 0.038 & -0.133 & 0.458 ** & -0.27 & 0.682 ** & 0.102 \\
\hline & & LMA & & & 1 & $-0.382 * *$ & -0.124 & $0.287^{* *}$ & $0.525 * *$ & $0.453 * *$ & 0.005 & $-0.314^{* *}$ & $0.475 * *$ & $-0.356 * *$ & $0.651 * *$ & $0.223 * *$ \\
\hline \multirow{4}{*}{4} & \multirow{4}{*}{ NO_NATIVES } & High & & & & 1 & $0.319^{*}$ & $-0.728^{* *}$ & $0.419^{\text {** }}$ & $-0.725^{* *}$ & -0.228 & 0.342 * & 0.134 & $0.931^{* *}$ & -0.188 & $-0.438^{* *}$ \\
\hline & & Medium & & & & 1 & $0.623 * *$ & $-0.644^{* *}$ & $0.433^{* *}$ & $-0.784 * *$ & $-0.390^{* *}$ & $0.417^{* *}$ & 0.209 & $0.918^{* *}$ & $-0.364 *$ & $-0.625 * *$ \\
\hline & & Low & & & & 1 & $0.836 * *$ & -0.528 ** & 0.397 * & -0.485 ** & $-0.341^{*}$ & $\begin{array}{l}-0.025 \\
-17\end{array}$ & 0.144 & $0.871^{* * *}$ & -0.105 & -0.324 * \\
\hline & & LMA & & & & 1 & $0.541^{* *}$ & $-0.624 * *$ & 0.391 ** & $-0.640^{* *}$ & $-0.331 * *$ & 0.249 ** & 0.057 & $0.893 * *$ & $-0.300^{* *}$ & $-0.499^{* *}$ \\
\hline \multirow{4}{*}{5} & \multirow{4}{*}{ RECYCLED/100 INH } & High & & & & & 1 & 0.079 & $0.421^{* *}$ & -0.145 & -0.208 & -0.036 & $0.358^{*}$ & $0.303^{*}$ & 0.227 & -0.166 \\
\hline & & Medium & & & & & 1 & -0.287 & 0.453 ** & $-0.435^{* *}$ & -0.28 & 0.264 & $0.294^{*}$ & $0.540 * *$ & -0.079 & $-0.401^{* *}$ \\
\hline & & Low & & & & & 1 & $-0.510^{* *}$ & 0.212 & -0.342 & -0.241 & -0.036 & 0.256 & $0.739 * *$ & -0.158 & -0.245 \\
\hline & & LMA & & & & & 1 & $-0.249^{* *}$ & $0.333^{\text {** }}$ & $-0.237^{* *}$ & -0.228 * & 0.031 & $0.277^{* *}$ & $0.429 * *$ & -0.042 & -0.172 \\
\hline \multirow{4}{*}{6} & \multirow{4}{*}{ SOLAR_PV_USE } & High & & & & & & 1 & -0.244 & $0.648^{* *}$ & 0.088 & -0.269 & 0.003 & $-0.646^{* *}$ & 0.157 & $0.361^{*}$ \\
\hline & & Medium & & & & & & 1 & -0.251 & $0.578^{* *}$ & 0.166 & -0.274 & 0.044 & $-0.578^{* *}$ & 0.321 * & 0.496 ** \\
\hline & & Low & & & & & & 1 & 0.006 & $0.359 *$ & 0.397 * & $\begin{array}{l}-0.27+4 \\
-0.048\end{array}$ & $\begin{array}{l}0.0+4 \\
-0.04\end{array}$ & $-0.644 * *$ & 0.139 & $0.356 *$ \\
\hline & & LMA & & & & & & 1 & -0.153 & $0.472 * *$ & 0.191 * & $-0.195^{*}$ & 0.062 & $-0.573 * *$ & $0.229 * *$ & $0.377^{* *}$ \\
\hline \multirow{4}{*}{7} & \multirow{4}{*}{ UNIV } & High & & & & & & & 1 & -0.358 * & -0.138 & -0.049 & $0.714^{* *}$ & $0.416^{* *}$ & $0.535 * *$ & $-0.376^{* *}$ \\
\hline & & Medium & & & & & & & 1 & -0.106 & -0.549 ** & -0.271 & $0.759 * *$ & $0.345^{*}$ & $0.464 * *$ & -0.211 \\
\hline & & Low & & & & & & & 1 & 0.114 & -0.194 & -0.256 & $0.576^{* *}$ & 0.235 & $0.616^{* *}$ & 0.065 \\
\hline & & LMA & & & & & & & 1 & -0.013 & -0.320 ** & $-0.226^{* *}$ & $0.637^{* *}$ & $0.245^{* *}$ & 0.465 ** & -0.105 \\
\hline \multirow{4}{*}{8} & \multirow{4}{*}{ HH_SIZE } & High & & & & & & & & 1 & $-0.346^{*}$ & $-0.525^{* *}$ & 0.032 & $-0.717^{* *}$ & 0.203 & $0.331^{*}$ \\
\hline & & Medium & & & & & & & & 1 & -0.039 & $-0.712 * *$ & 0.143 & $-0.741^{* *}$ & $0.726 * *$ & $0.742 * *$ \\
\hline & & Low & & & & & & & & 1 & $0.429^{* *}$ & $-0.352 *$ & 0.335 & $-0.719^{* *}$ & 0.518 ** & $0.571^{* *}$ \\
\hline & & LMA & & & & & & & & 1 & 0.097 & $-0.546^{* *}$ & $0.408^{* *}$ & $-0.753^{* *}$ & 0.690 ** & $0.739 * *$ \\
\hline \multirow{4}{*}{9} & \multirow{4}{*}{ R_AGE_DEP } & High & & & & & & & & & 1 & 0.248 & $-0.402^{* *}$ & -0.155 & -0.103 & 0.256 \\
\hline & & Medium & & & & & & & & & 1 & 0.272 & $-0.473 * *$ & -0.414 ** & -0.236 & 0.086 \\
\hline & & Low & & & & & & & & & 1 & -0.057 & -0.193 & -0.556 ** & -0.158 & $0.382 *$ \\
\hline & & LMA & & & & & & & & & 1 & 0.099 & $-0.346 * *$ & $-0.318^{* *}$ & -0.16 & 0.203 * \\
\hline & & High & & & & & & & & & & 1 & -0.137 & $0.314^{*}$ & -0.206 & -0.18 \\
\hline & & Medium & & & & & & & & & & 1 & $-0.299 *$ & $0.411^{* *}$ & $-0.681^{* *}$ & $-0.568 * *$ \\
\hline 10 & LONE_FAMILIES & Low & & & & & & & & & & 1 & -0.295 & 0.193 & $-0.325 *$ & -0.289 \\
\hline & & LMA & & & & & & & & & & 1 & $-0.436 * *$ & $0.468 * *$ & $-0.502 * *$ & $-0.446 * *$ \\
\hline & & High & & & & & & & & & & & 1 & 0.05 & $0.628 * *$ & $-0.279 *$ \\
\hline & & Medium & & & & & & & & & & & 1 & 0.013 & $0.648^{* *}$ & 0.058 \\
\hline 11 & AV_RENT & $\begin{array}{l}\text { Medium } \\
\text { Low }\end{array}$ & & & & & & & & & & & 1 & -0.093 & $0.697 * *$ & 0.15 \\
\hline & & LMA & & & & & & & & & & & 1 & $-0.199 *$ & $0.757^{* *}$ & $0.342 * *$ \\
\hline
\end{tabular}


Table 3. Cont.

\begin{tabular}{|c|c|c|c|c|c|c|c|c|c|c|c|c|c|c|c|c|}
\hline & & & 1 & 2 & 3 & 4 & 5 & 6 & 7 & 8 & 9 & 10 & 11 & 12 & 13 & 14 \\
\hline \multirow{4}{*}{12} & \multirow{4}{*}{ RENTED } & $\begin{array}{l}\text { High } \\
\end{array}$ & & & & & & & & & & & & 1 & -0.227 & $-0.470^{* *}$ \\
\hline & & Medium & & & & & & & & & & & & 1 & $-0.429 * *$ & $-0.675^{\text {** }}$ \\
\hline & & Low & & & & & & & & & & & & 1 & -0.282 & $-0.570^{* *}$ \\
\hline & & LMA & & & & & & & & & & & & 1 & $-0.487^{* *}$ & -0.675 ** \\
\hline \multirow{4}{*}{13} & \multirow{4}{*}{$\mathrm{TB}>200$} & High & & & & & & & & & & & & & 1 & 0.248 \\
\hline & & Medium & & & & & & & & & & & & & 1 & 0.546 ** \\
\hline & & Low & & & & & & & & & & & & & 1 & $0.372 *$ \\
\hline & & LMA & & & & & & & & & & & & & 1 & $0.611^{* *}$ \\
\hline \multirow{4}{*}{14} & \multirow{4}{*}{ TB_SH } & High & & & & & & & & & & & & & & 1 \\
\hline & & Medium & & & & & & & & & & & & & & 1 \\
\hline & & Low & & & & & & & & & & & & & & 1 \\
\hline & & LMA & & & & & & & & & & & & & & 1 \\
\hline
\end{tabular}

${ }^{*}$ Correlation is significant at the 0.05 level (2-tailed); ${ }^{* *}$ Correlation is significant at the 0.01 level (2-tailed); Correlation is significant at $p<0.001$ in bold 
Table 4. Summary and loadings ( $>0: 30$ ) on the principal component.

\begin{tabular}{|c|c|c|c|c|c|c|c|c|c|c|c|c|c|}
\hline & & \multicolumn{3}{|c|}{ ALL STUDY AREA } & \multicolumn{3}{|c|}{ GROUP_A } & \multicolumn{3}{|c|}{ GROUP_B } & \multicolumn{3}{|c|}{ GROUP_C } \\
\hline & & & & & \multicolumn{3}{|c|}{ High Coverage } & \multicolumn{3}{|c|}{ Medium Coverage } & \multicolumn{3}{|c|}{ Low Coverage } \\
\hline Correlation Determinant & & \multicolumn{3}{|c|}{0.000000226} & \multicolumn{3}{|c|}{0.000000118} & \multicolumn{3}{|c|}{0.0000000643} & \multicolumn{3}{|c|}{0.000000032} \\
\hline \multicolumn{2}{|c|}{ Rotation converged in iterations } & \multicolumn{3}{|c|}{5} & \multicolumn{3}{|c|}{5} & \multicolumn{3}{|c|}{8} & \multicolumn{3}{|c|}{7} \\
\hline KMO & Meas. of samp. adeq. & \multicolumn{3}{|c|}{0.802} & \multicolumn{3}{|c|}{0.735} & \multicolumn{3}{|c|}{0.624} & \multicolumn{3}{|c|}{0.766} \\
\hline Bartlett'sTest of Sphericity & $\begin{array}{l}\text { Approx. Chi-Square } \\
\text { df } \\
\text { Sig. }\end{array}$ & \multicolumn{3}{|c|}{$\begin{array}{c}1721.817 \\
91 \\
0.00\end{array}$} & \multicolumn{3}{|c|}{$\begin{array}{c}454.735 \\
91 \\
0.00\end{array}$} & \multicolumn{3}{|c|}{$\begin{array}{l}521.641 \\
91 \\
0.00\end{array}$} & \multicolumn{3}{|c|}{$\begin{array}{l}681.619 \\
91 \\
0.00\end{array}$} \\
\hline $\begin{array}{l}\text { Rotation Sums of Sq. } \\
\text { Loadings }\end{array}$ & $\begin{array}{l}\text { Total } \\
\% \text { of Variance } \\
\text { Cumulative \% }\end{array}$ & $\begin{array}{l}3.773 \\
26.948 \\
26.948 \\
\end{array}$ & $\begin{array}{l}3.657 \\
26.125 \\
53.073 \\
\end{array}$ & $\begin{array}{l}3.182 \\
22.732 \\
75.805\end{array}$ & $\begin{array}{l}4.937 \\
35.265 \\
35.265\end{array}$ & $\begin{array}{l}3.646 \\
26.045 \\
61.310 \\
\end{array}$ & $\begin{array}{l}1.938 \\
13.841 \\
75.151\end{array}$ & $\begin{array}{l}3.737 \\
26.696 \\
26.696\end{array}$ & $\begin{array}{l}3.484 \\
24.882 \\
51.578\end{array}$ & $\begin{array}{l}3.140 \\
22.428 \\
74.006\end{array}$ & $\begin{array}{l}4.764 \\
34.03 \\
34.03\end{array}$ & $\begin{array}{c}3.948 \\
28.2 \\
62.23\end{array}$ & $\begin{array}{l}2.279 \\
16.28 \\
78.52\end{array}$ \\
\hline \multicolumn{2}{|c|}{ Cronbach's Alpha coefficients } & \multicolumn{3}{|c|}{0.874} & \multicolumn{3}{|c|}{0.878} & \multicolumn{3}{|c|}{0.882} & \multicolumn{3}{|c|}{0.888} \\
\hline Thematic Domain & Variable & $\mathrm{PC} 1$ & PC2 & PC3 & PC1 & PC2 & PC3 & PC1 & $\mathrm{PC} 2$ & PC3 & PC1 & PC2 & PC3 \\
\hline \multirow{3}{*}{$\begin{array}{l}\text { Human smart } \\
\text { characteristics }\end{array}$} & $\begin{array}{l}\text { COMPUT_USE } \\
\text { INTERN_USE } \\
\text { KIS }\end{array}$ & $\begin{array}{l}0.712 \\
0.738 \\
0.840\end{array}$ & \multirow{3}{*}{-0.461} & & $\begin{array}{l}0.374 \\
0.373\end{array}$ & 0.848 & $\begin{array}{l}-0.325 \\
0.471\end{array}$ & 0.348 & 0.690 & $\begin{array}{l}0.583 \\
0.744 \\
0.656\end{array}$ & $\begin{array}{l}0.914 \\
0.783 \\
0.838\end{array}$ & & 0.383 \\
\hline & $\begin{array}{l}\text { NO_NATIVES } \\
\text { RECYCLED/100 } \\
\text { SOLAR_PV_USE }\end{array}$ & & & $\begin{array}{l}0.839 \\
0.671 \\
-0.702\end{array}$ & $\begin{array}{l}-0.967 \\
-0.530 \\
0.890\end{array}$ & & 0.504 & $\begin{array}{l}-0.957 \\
-0.439 \\
0.763\end{array}$ & & $\begin{array}{l}0.464 \\
0.319\end{array}$ & & $\begin{array}{l}0.763 \\
0.479\end{array}$ & $\begin{array}{l}-0.578 \\
-0.680 \\
0.850\end{array}$ \\
\hline & UNIV & 0.841 & & 0.415 & -0.408 & 0.834 & & -0.373 & 0.371 & 0.740 & 0.828 & 0.386 & \\
\hline Demographic dynamics & $\begin{array}{l}\text { HH_SIZE } \\
\text { R_AGE_DEPEND } \\
\text { LONE_FAMILIES }\end{array}$ & -0.327 & $\begin{array}{l}0.842 \\
-0.359 \\
-0.761\end{array}$ & $\begin{array}{l}-0.374 \\
-0.651\end{array}$ & 0.874 & & $\begin{array}{l}-0.385 \\
0.910\end{array}$ & $\begin{array}{l}0.650 \\
0.360\end{array}$ & $\begin{array}{l}0.649 \\
-0.663 \\
-0.845\end{array}$ & -0.352 & $\begin{array}{l}0.461 \\
-0.455\end{array}$ & $\begin{array}{l}-0.760 \\
-0.522 \\
0.668\end{array}$ & $\begin{array}{l}0.306 \\
0.347\end{array}$ \\
\hline \multirow[b]{2}{*}{ Built Infrastucture } & AV_RENT & 0.745 & 0.447 & & & 0.900 & & & 0.528 & 0.756 & 0.818 & & \\
\hline & $\begin{array}{l}\text { RENTED } \\
\text { TB > } 200 \\
\text { TB_SH }\end{array}$ & 0.660 & $\begin{array}{l}-0.586 \\
0.653 \\
0.793\end{array}$ & 0.718 & $\begin{array}{l}-0.934 \\
0.350 \\
0.656\end{array}$ & $\begin{array}{l}0.757 \\
-0.402\end{array}$ & 0.385 & -0.913 & $\begin{array}{l}0.707 \\
0.580\end{array}$ & 0.423 & 0.855 & 0.833 & -0.441 \\
\hline
\end{tabular}


From the interpretive point of view, the major merit of PCA resides in the possibility to give a meaningful variables interaction to the components. Interpretation is based on component loadings, that is, on the correlation coefficients between original variables and the components. The extracted dimensions represent the linearly independent systems organizing the data. The variables more correlated with the components are the ones that contribute to component meaning. Each variable participates in all the extracted components, to different degrees, so fulfilling the notion that the same variable can participate in more than one explanation. Regarding the Overall Study Area (OSA), PC1 accounts for approximately $26.95 \%$ of the variance and demonstrates high positive coefficients for high education attainment, employment in the KIS industry, and IT skills (internet and computer use), reflecting to a modern and educated resident profile. Moreover, high average rent and large apartments are equally high positive coefficients. PC2 accounts for an additional $26.13 \%$ of the variance and includes large households, accommodated in large apartments, mainly in single houses, with IT skills, showing negative coefficient with rented housing and lone families. Finally, PC3, accounting for an additional $22.73 \%$ of the variance, can be described as the "foreigner's component", showing high rented and recycling figures, low solar use figures, and normally low age dependency rates. This component is clearly pointing to a high concentration of foreigners coming to Limassol for work. Thus, the OSA pattern may be summarized as follows:

- $\quad$ OSA PC1 (KIS employed, university and IT educated),

- $\quad$ OSA PC2 (high $\mathrm{H} / \mathrm{H}$ size, single housing) and

- $\quad$ OSA PC3 (high \% of foreigners, rented housing and high recycling rates)

In the high coverage area (Group_A), PC1 accounted for approximately $35.26 \%$ of the variance and included high positive coefficients such as use of solar and voltaic systems and household size and high negatives such as non-native residents and rented housing. This component shows similar characteristics with OSA PC2. In addition, PC2 accounts for $26.04 \%$ of the variance and includes the concept of high monthly average rent with residents of high educational attainment, employed in knowledge intensive industries and computer use. This component shows similar characteristics with OSA PC1. The third component accounts additionally for $13.84 \%$ of the variance and is defined mainly by a high positive coefficient of ratio age dependency which is combined with a slightly negative household size coefficient. In this component the dominant attribute is old age (0.910) with moderate correlations with recycling and employed in KIS industry. It is worth mentioning that in this high coverage area, including the central locations of the study area, the variable "ratio age dependency" demonstrates the highest loading score (0.910), an absolute expectation as long as the older population $(65+)$ tends to live there.

The OSA pattern has a similar behavior in the high coverage area (Group_A). However, instead of OSA PC3, a 13.84\% of variance is explained by elderly residents, with the highest recorded age dependency rates. This is well explained, given that the high coverage area is mainly the traditional city center of Limassol. In the medium coverage area (Group_B), for PC1, the picture is almost the same, with a small decrease of the numbers. Our attention must be focused on PC2, with an equal to PC1 concentration of large families living in large single houses. Citizens are fairly educated, connected with the creative industry and well familiar with the new technologies. Finally, PC3 has characteristics quite like OSA PC1. The OSA pattern has a different behavior in the medium coverage area (Group_B), representing the first expansion zone of the city center. OSA PC2 records high percentages, in two different options (the traditional locals and the younger traditional), summing up to an approximate $52 \%$ of the variance. Of the variance, $22.42 \%$ is explained by OSA PC1. Again, in the medium coverage area, OSA PC3 is not recorded. In the low coverage area (Group_C), PC1 represents areas with mixed population (natives and non-natives), strong human smart characteristics, large apartments, expensive rents, and above average household size, similar behavior to OSA PC1. On the other hand, PC2 is strongly related with the presence of non-natives, fairly educated, well familiar with recycling, mostly living in rented medium to small apartments, in small or lone families, similar behavior to OSA PC3. 
Finally, PC3 is characterized by the strong presence of locals, related with large household size and age dependency, demonstrating also a high interest in the use of solar and voltaic systems, similar behavior to OSA PC2.

The OSA pattern is repeated in low coverage areas (Group_C), with only a slight but meaningful difference. OSA PC 3 increases its percentage of variance to $28.2 \%$, from $22.73 \%$, in the OSA. On the other hand, OSA PC2 shows a decrease of $16.2 \%$ of variance, compared with $26.12 \%$ in the overall study area. This is mainly due to the high concentration of foreigners in the low coverage area. The spatial dispersion of OSA in the study area varies widely in degree and mode. (Figure 7). The spatial distribution of OSA1 shows high positive concentrations (in red colors) at the outskirts of city expansion (low coverage areas), especially in the north and east, where high rates of population concentration are observed with high ICT skills and tertiary education. The lowest rates (in blue colors) are observed mainly in the coastal zone, where houses are small, as well as in the western region, where rents are low. In areas with almost zero deviation (Std. Dev. -0.50-0.50), with yellow color, OSA is almost uninteresting. OSA2 shows a slightly different spatial distribution. Almost throughout the low coverage area, OSA2 shows the highest rates, except for remote areas (west and east). On the other hand, as expected, the lowest rates are observed in the high and moderate coverage areas, where the household size is quite low and single houses show a low concentration. Finally, the spatial variation of OSA3 is quite interesting. The high rates are observed in eastern and coastal areas, due to the higher rates of non-indigenous residents, while the lowest rates are observed in the west and north.

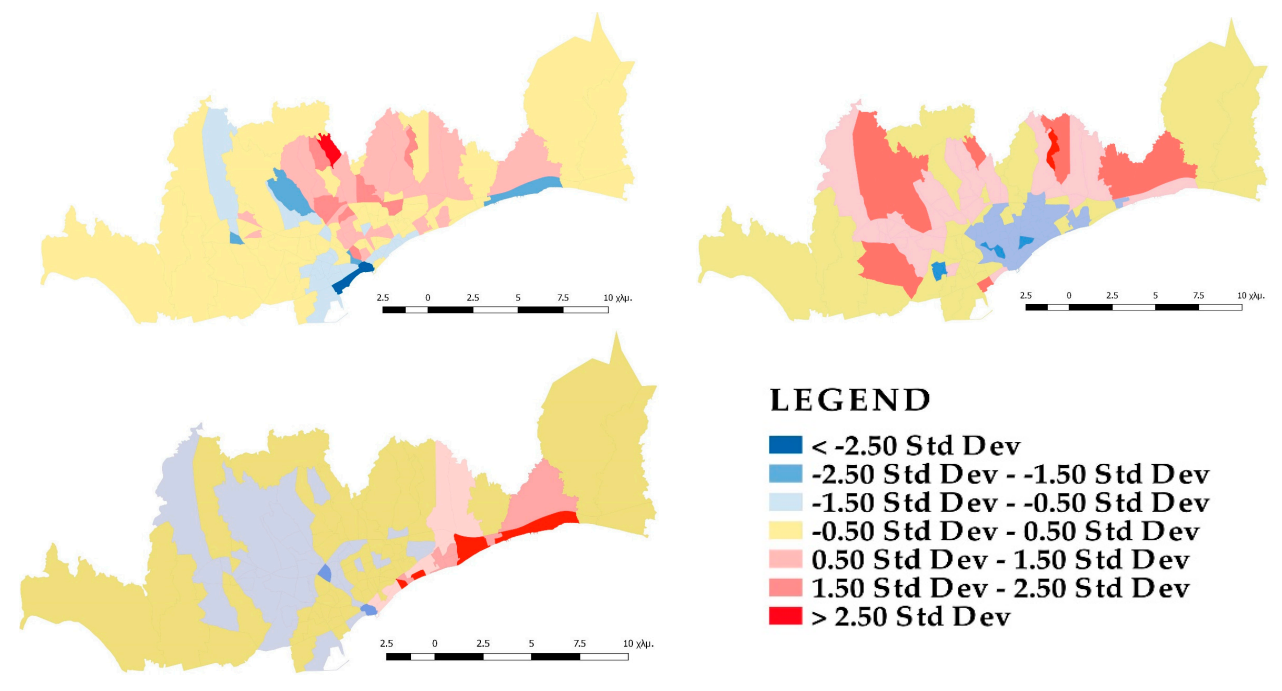

Figure 7. Spatial distribution of Overall Study Area (OSA) components.

\section{Discussion}

The scope of this study was to examine the local urban challenges affecting human smart characteristics in Limassol metropolitan area, the southernmost European urban agglomeration, Cyprus. Regarding the limitations of the study, it should be mentioned that due to the limited number of observations (136 postal codes), it is almost impossible to generalize from this sample size. Following this, it should be pointed here that this quantitative study is the initial stage of ongoing research and consultation of all the actors in smart city vision to better understand the human-centered smart city indices and their influence in the phenomena of local city challenges in more detail. Moreover, the study utilized a data set from the latest population census (2011) available in Cyprus. This gives credibility to the data used, because a specific methodology was followed, common to all European states. On the other hand, the data set is rather old and outdated, as the elements observed are rather dynamic, they change and are affected by external factors.

From the statistical analysis three factors were extracted with total cumulative variance of $75.8 \%$. The first factor (PC1) could be labeled as "high educated population" and consists of high positive 
correlations between tertiary attainment education, employment in Knowledge Intensive Services (KIS), average monthly rent, ICT skills, and houses with more than $200 \mathrm{~m}^{2}$ cover area. The second factor (PC2), labeled as "traditional Cypriot families", consists of large household size, living, as expected, in houses with high-standard amenities (e.g., single houses and those covering a large area) with moderate ICT skills. The third factor (PC3), labeled as "non-native population", includes high positive interaction between residents having a country of birth other than Cyprus, rented housing with moderate housing amenities, and high recycling rates. On the other hand, negative interactions appeared with the use of renewable energy, age and household size.

Comparing our findings with similar studies conducted we can identify both similarities and differences. Our findings are aligned with similar studies in regard to ICT skills in that they are unequally distributed among individuals with different demographic characteristics such as age, gender, socioeconomic status, education level, and ethnicity [75-78]. Furthermore, insights from other studies show that environmental awareness (as an expression of households' renewable use and recycling) appears positively influenced by educational attainment, population age, and family income. Specifically, young people with higher educational attainment and a higher income level are more aware of environmental issues $[79,80]$.

The above-mentioned key findings of the research are proving themselves in the three different sub-groups, extracted from CLC 2012 continuous urban fabric (SL > 80\%), high, medium, and low coverage areas, in different ways highlighting the way that urban characteristics are affecting human behaviors. In high coverage areas (Group_A), the intensity of the key findings of our research is interesting in the case of the concentration of high education level citizens demonstrating higher numbers and stronger relationships between the variables involved. Equally, regarding the concentration of Cypriots, the picture is strong and clear with a straight counter relationship between household size and the concentration of rented housing and non-native residents. In the case of non-natives, normally there are no interesting findings because of the nature of the high coverage areas that are characterized by a strong presence of elderly citizens, which leads to 0.910 age-dependency ratio. This seems also to be related with the acceptable level of recycling together with an expected concentration of employees in KIS. Regarding the demographic dynamics, in the low coverage area (Group_C) the average household size is well above the average of the study area (2.84), demonstrating the concentration of families with children. This view is reinforced by the fact that in this area the age dependency index is lower than the average of the study area (39.92).

The population with human smart characteristics displays diversity, regarding its installation depending on the variable under consideration. The well-qualified citizens (having at least a university degree) tend to live in areas outside the city center where built infrastructure is better. The same is true for the employees in KIS. Where small percentages of rented housing are observed, there is a higher percentage of solar and voltaic use and a high concentration of native inhabitants. The percentages of household internet use are homogeneous in all three areas under consideration, with very small differences between them. Finally, household computer use is more varied, recording $71.74 \%$ in Group_C, noticeably above the average (64.59\%) in the OSA. Regarding the built infrastructure, we notice that the three variables average monthly rent, single housing concentration, and average house size rise as we move away from the city center. The urban expansion of the city during the last four decades results in the development of spacious modern housing, with upgraded facilities in larger plots. This urban expansion normally pushes the cost of apartments and houses higher.

The results of this study have specific policy implications. By application of the statistical and spatial analysis, it is established that a variety of factors could be the main determinants (in implementing policies for anthropocentric smart cities) in different neighborhoods. The proposed European Union Cohesion Policy Plan 2021-2027 for Cyprus needed to break through the narrow perspective of smart city notion and take socioeconomic and morphological aspects into consideration in a bottom-up approach. Strengthening the local economy in research and innovation (knowledge intensive industry and creative economy) with the introduction of smart specialization areas, in areas with a high 
concentration of employees in these sectors, will result in improved employability. Targeted actions to reduce the digital gap in the population, through lifelong learning, are needed to achieve the goal of digital transformation and boost the uptake of ICT by citizens and business. High levels of migration, in comparison with other European countries, require policies to support social inclusion and long-term integration measures. Accelerating the transition to a circular economy by increasing awareness measures of recycling (waste separation/reuse) in areas with low concentrations and renewable power generation remains underexploited. Revitalizing the city center (urban core area face depopulation) with appropriate policies for attracting people and businesses and renovating the aged residential building stock (mainly in the city center) with energy efficient measures are also needed.

It is obvious that smart cities, although specifically developed as an idea during the past 20 years, have a long history dating back to the previous century's visions about urban futures. Although elusive, the visions were and continue to be an essential part of urban planning and development discipline, and they have always been urging us to move forward [8]. Political willingness and long-term commitment are two of the key factors that need to be taken into account for the implementation of the human-centered smart city vision. Strategic vision is profoundly related to long-term commitment and will provide continuity beyond routine election-related changes in cities. Tackling common and local challenges should be the priority and these challenges need to have a direct relation to the demands from citizens, cities, regions, and the country [81]. Local challenges should also be considered and influence the project selection process.

\section{Conclusions}

This paper analyzed smart human characteristics and identified the local determinants, regarding demographic dynamics and built infrastructure attributes, which should be addressed and prioritized to apply effective smart city policies in the LMA. Prior to statistical analysis, two reviews were made in order to answer the research questions. The first one was conducted to identify the human smart characteristics within the concept of the smart city notion, and the second one was conducted to specify the local challenges that the urban agglomeration of LMA addressed, through literature review on smart cities and local studies. From the above reviews, 14 variables were deemed necessary for processing which consist of three categories: human smart characteristics (7), demographic dynamics (3), and built infrastructure attributes (4).

The inspection of the PCA-extracted components showed the existence of strong correlations between smart human characteristics and local attributes. For individual computer use, strong positive correlations were observed with average rent and large houses, and a negative correlation was observed with age dependency ratio, in all sub-groups. With regards employed in KIS, strong correlations were observed with average rent, large houses, and household size. For foreigner residents, positive correlations were observed with rented housing, while a negative correlation was observed with household size. Rented houses defined strong positive correlations with recycling habits and negative correlations with household solar use, while population with high education showed positive correlations with average rent and large houses.

Author Contributions: This paper represents the results of collegial teamwork. The authors designed the research jointly. M.N.A. and K.T. conducted the literature review and prepared the first draft of the manuscript. P.C.K. and D.G.H. finalized the manuscript. All authors have read and agreed to the published version of the manuscript.

Funding: This research received no external funding.

Acknowledgments: The authors acknowledge the 'EXCELSIOR' (ERATOSTHENES: Excellence Research Centre for Earth Surveillance and Space-Based Monitoring of the Environment) project (www.excelsior2020.eu). This project has received funding from the European Union's Horizon 2020 research and innovation programme under Grant Agreement No 857510. This project has received funding from the Government of the Republic of Cyprus through the Directorate General for the European Programmes, Coordination and Development. The authors also would like to acknowledge the "CUT Open Access Author Fund" for covering the open access publication fees of the paper.

Conflicts of Interest: The authors declare no conflict of interest. 


\section{References}

1. Albino, V.; Berardi, U.; Dangelico, R.M. Smart cities: Definitions, dimensions, performance, and initiatives. J. Urban Technol. 2015, 22, 3-21. [CrossRef]

2. Chourabi, H.; Nam, T.; Walker, S.; Gil-Garcia, J.R.; Mellouli, S.; Nahon, K.; Scholl, H.J. Understanding smart cities: An integrative framework. In Proceedings of the 45th Hawaii International Conference on System Sciences (IEEE), Maui, HI, USA, 4-7 January 2012.

3. Meijer, A.; Bolivar, M.P.R. Governing the Smart City: A review of the literature on smart urban governance. Int. Rev. Adm. Sci. 2015, 82, 392-408. [CrossRef]

4. Nam, T.; Pardo, T.A. Conceptualizing Smart City with dimensions of technology, people, and institutions. In Proceedings of the 12th Annual International Conference on Digital Government Research, College Park, MD, USA, 12-15 June 2011. [CrossRef]

5. CEC. Cities of Tomorrow; Council of European Community: Bruxelles, Belgium, 2011.

6. Bibri, S.E.; Krogstie, J. Smart sustainable cities of the future: An extensive interdisciplinary literature review. Sustain. Cities Soc. 2017, 31, 183-212. [CrossRef]

7. Caragliu, A.; Del Bo, C.; Nijkamp, P. Smart cities in Europe. J. Urban Technol. 2011, 18, 65-82. [CrossRef]

8. Thompson, E.M. Smart City: Adding to the Complexity of Cities. In Complexity \& Simplicity-Proceedings of the 34th eCAADe Conference; University of Oulu: Oulu, Finland, 2016; Volume 1, pp. 651-660.

9. BSI. Smart Cities_Vocabulary (PAS 180:2014, 3.1.62); British Standards Institution: London, UK, 2014.

10. Gil-Garcia, J.R.; Pardo, T.A.; Nam, T.A. A Comprehensive View of the 21st Century City: Smartness as Technology and Innovation in Urban Contexts. In Smarter as the New Urban Agenda; Gil-Garcia, J.R., Pardo, T.A., Nam, T., Eds.; Springer: Cham, Switzerland, 2016.

11. Giffinger, R.; Fertner, C.; Kramar, H.; Kalasek, R.; Pichler-Milanovi, N.; Meijers, E. Smart Cities: Ranking of European Medium-Sized Cities; Centre of Regional Science, Vienna University of Technology: Vienna, Austria, 2007.

12. Giffinger, R.; Fertner, C.; Kramar, H.; Meijers, E. City-Ranking of European Medium-Sized Cities; Centre of Regional Science, Vienna University of Technology: Vienna, Austria, 2007; pp. 1-12.

13. Angelidou, M. Smart cities: A conjuncture of four forces. Cities 2015, 47, 95-106. [CrossRef]

14. Huovila, A.; Bosch, P.; Airaksinen, M. Comparative analysis of standardized indicators for Smart sustainable cities: What indicators and standards to use and when? Cities 2019, 89, 141-153. [CrossRef]

15. Manville, C.; Cochrane, G.; Cave, J.; Millard, J.; Pederson, J.K.; Thaarup, R.K.; Liebe, A.; Wissner, M.; Massink, R.; Kotterink, B. Mapping Smart Cities in the EU; DG for Internal Policies, European Parliament, Strasbourg: Brussels, Belgium, 2014.

16. Neirotti, P.; De Marco, A.; Cagliano, A.C.; Mangano, G.; Scorrano, F. Current trends in Smart City initiatives: Some stylised facts. Cities 2014, 38, 25-36. [CrossRef]

17. Monzon, A. Smart Cities Concept and Challenges. Bases for the Assessment of Smart City Projects. In Proceedings of the International Conference on Smart Cities and Green ICT Systems (SMARTGREENS), Lisbon, Portugal, 20-22 May 2015; pp. 1-11.

18. Batty, M. The New Science of Cities; MIT Press: Cambridge, MA, USA, 2013.

19. Zaman, A.U.; Lehmann, S. Challenges and opportunities in transforming a city into a "zero waste city". Challenges 2011, 2, 73-93. [CrossRef]

20. McGrath, B.; Pickett, S. The metacity: A conceptual framework for integrating ecology and urban design. Challenges 2011, 2, 55-72. [CrossRef]

21. Santana, E.S.; Nunes, E.O.; Santos, L.B. The use of ISO 37122 as standard for assessing the maturity level of a smart city. Int. J. Adv. Eng. Res. Sci. 2018, 5, 12. [CrossRef]

22. Nicolaou, A.; Parmaxi, A.; Papadima-Sophocleous, S.; Boglou, D. Language education in a multilingual city: The case of Limassol. Lond. Rev. Educ. 2016, 14, 174-185. [CrossRef]

23. Russo, F.; Rindone, C.; Panuccio, P. European plans for the smart city: From theories and rules to logistics test case. Eur. Plan. Stud. 2016, 24, 1709-1726. [CrossRef]

24. Angelidou, M. Smart city policies: A spatial approach. Cities 2014, 41, 3-11. [CrossRef]

25. Dameri, R.P.; Rosenthal-Sabroux, C. Smart City: How to Create Public and Economic Value with High Technology in Urban Space; Springer: Basel, Switzerland, 2014; ISBN 978-3-319-06159-7. 
26. Andreani, S.; Kalchschmidt, M.; Pinto, R.; Sayegh, A. Reframing technologically enhanced urban scenarios: A design research model towards human centered smart cities. Technol. Forecast. Soc. Chang. 2018, 142, $15-25$. [CrossRef]

27. Zygiaris, S. Smart city reference model: Assisting planners to conceptualize the building of smart city innovation ecosystems. J. Knowl. Econ. 2013, 4, 217-231. [CrossRef]

28. Popescu, G.H. The economic value of smart city technology. Econ. Manag. Financ. Mark. 2015, 10, 76-82. Available online: https://www.ceeol.com/search/article-detail?id=306532 (accessed on 30 November 2019).

29. Anttiroiko, A.V. Smart cities: Building platforms for innovative local economic restructuring. In Transforming City Governments for Successful Smart Cities; Rodríguez-Bolívar, M.P., Ed.; Springer: Cham, Switzerland, 2015; pp. 23-42. ISBN 978-3-319-03166-8.

30. Kourtit, K.; Nijkamp, P. In praise of megacities in a global world. Reg. Sci. Policy Pract. 2013, 5, 167-182. [CrossRef]

31. Berry, C.R.; Glaeser, E.L. The divergence of human capital levels across cities. Pap. Reg. Sci. 2005, 84, 407-444. [CrossRef]

32. Glaeser, E.L.; Berry, C.R. Why are smart places getting smarter. In Rappaport Institute for Greater Boston; Policy Briefs, PB-2006-2; Taubman Centre for State and Local Government: Cambridge, MA, USA, 2006; Available online: https://www.hks.harvard.edu/sites/default/files/centers/taubman/files/brief_divergence.pdf (accessed on 12 December 2018).

33. Shapiro, J.M. Smart cities: Quality of life, productivity, and the growth effects of human capital. Rev. Econ. Stat. 2006, 88, 324-335. [CrossRef]

34. Hollands, R.G. Will the real Smart City please stand up? Intelligent, progressive or entrepreneurial? City 2008, 12, 303-320. [CrossRef]

35. Winters, J.V. Why are smart cities growing? Who moves and who stays. J. Reg. Sci. 2011, 51, 253-270. [CrossRef]

36. Carli, R.; Dotoli, M.; Pellegrino, R.; Ranieri, L. Measuring and Managing the Smartness of Cities: A Framework for Classifying Performance Indicators. In Proceedings of the IEEE Systems, Man, and Cybernetics, Manchester, UK, 13-16 October 2013. [CrossRef]

37. Lazaroiu, G.C.; Roscia, M. Definition methodology for the smart cities model. Energy 2012, 47, $326-332$. [CrossRef]

38. Kourtit, K.; Macharis, C.; Nijkamp, P. A multi-actor multi-criteria analysis of the performance of global cities. Appl. Geogr. 2014, 49, 24-36. [CrossRef]

39. Esmaeilpoorarabi, N.; Yigitcanlar, T.; Guaralda, M. Place quality and urban competitiveness symbiosis? A position paper. Int. J. Knowl.-Based Dev. 2016, 7, 4-21. [CrossRef]

40. Komninos, N. Intelligent cities: Towards interactive and global innovation environments. Int. J. Innov. Reg. Dev. 2009, 1, 337-355. [CrossRef]

41. Yigitcanlar, T. Smart cities: An effective urban development and management model? Aust. Plan. 2015, 52, 27-34. [CrossRef]

42. Lombardi, P.; Giordano, S.; Farouh, H.; Wael, Y. An analytic network model for Smart cities. In Proceedings of the 11th International Symposium on the Analytic Hierarchy Process, Sorrento, Italy, 15-18 June 2011.

43. Ben Letaifa, S. How to strategize smart cities: Revealing the SMART model. J. Bus. Res. 2015, 68, 1414-1419. [CrossRef]

44. Barrionuevo, J.M.; Berrone, P.; Ricart, J.E. Smart cities, sustainable progress. IESE Insight 2012, 14, 50-57. Available online: https://www.researchgate.net/profile/Pascual_Berrone/publication/276088190_Smart_ Cities_Sustainable_Progress_Opportunities_for_Urban_Development/links/563f9a3908ae8d65c0150f53. pdf (accessed on 30 November 2019).

45. Yigitcanlar, T. Innovating urban policymaking and planning mechanisms to deliver knowledge-based agendas: A methodological approach. Int. J. Knowl.-Based Dev. 2014, 5, 253-270. [CrossRef]

46. Dirks, S.; Keeling, M. A Vision of Smarter Cities: How Cities Can Lead the Way into a Prosperous and Sustainable Future; IBM Global Business Services: Somers, NY, USA, 2009; Available online: https://pdfs.semanticscholar. org/e46b/641d546a348df63762b8ce79b23911568f36.pdf (accessed on 21 November 2018).

47. Hughes, S.; Pincetl, S.; Boone, C. Triple exposure: Regulatory, climatic, and political drivers of water management in Los Angeles. Cities 2013, 32, 51-69. [CrossRef] 
48. Toppeta, D. The Smart City Vision: How Innovation and ICT Can Build Smart, "Livable", Sustainable Cities. Innov. Knowl. Found. 2010, 5, 1-9. Available online: http://www.thinkinnovation.org/file/research/23/en/ Toppeta_Report_005_2010.pdf (accessed on 21 February 2018).

49. Atzori, L.; Iera, A.; Morabito, G. The internet of things: A survey. Comput. Netw. 2010, 54, $2787-2805$. [CrossRef]

50. Mahizhnan, A. Smart cities. The Singapore case. Cities 1999, 16, 13-18. [CrossRef]

51. Bakıcı, T.; Almirall, E.; Wareham, J. A Smart City initiative: The case of Barcelona. J. Knowl. Econ. 2013, 4, 135-148. [CrossRef]

52. Fernandez-Anez, V.; Fernández-Güell, J.M.; Giffinger, R. Smart City implementation and discourses: An integrated conceptual model. The case of Vienna. Cities 2018, 78, 4-16. [CrossRef]

53. Niemeijer, D.; de Groot, R.S. A conceptual framework for selecting environ-mental indicator sets. Ecol. Indic. 2008, 8, 14-25. [CrossRef]

54. Spangenberg, J. Environmental space and the prism of sustainability: Frameworks for indicators measuring sustainable development. Ecol. Indic. 2002, 2, 295-309. [CrossRef]

55. Bossel, H. Indicators for Sustainable Development: Theory, Method, Applications; International Institute for Sustainable Development: Winnipeg, MB, Canada, 1999.

56. Duinker, P. Criteria and indicators of sustainable forest management in Canada: Progress and problems in integrating science and politics at the local level. In Criteria and Indicators for Sustainable Forest Management at the Forest Management Unit Level; Franc, A., La roussinie, O., Karjalainen, T., Eds.; European Forest Institute Proceedings: Joensuu, Finland; Gummerus Printing: Saarijarvi, Finland, 2001; Volume 38, pp. 7-27.

57. Miller, G. The development of indicators for sustainable tourism: Results of a Delphi survey of tourism researchers. Tour. Manag. 2001, 22, 351-362. [CrossRef]

58. Liverman, D.M.; Hanson, M.E.; Brown, B.J.; Meredith, R.W. Global sustainability: Toward Measurement. Environ. Manag. 1988, 20, 133-143. [CrossRef]

59. Guy, G.B.; Kibert, C.J. Developing Indicators of Sustainability: US experience. Build. Res. Inf. 1998, 26, 39-45. [CrossRef]

60. Smoyer-Tomic, K.; Hewko, J.; Hodgson, J. Spatial accessibility and equity of playgrounds in Edmonton, Canada. Can. Geogr. 2004, 48, 287-302. [CrossRef]

61. Kuzyk, L. The ecological footprint housing component: A geographic information system analysis. Ecol. Indic. 2011, 16, 31-39. [CrossRef]

62. Kolossov, V.; Vendina, O.; O'Loughlin, J. Moscow as an Emergent World City: International Links, Business Developments, and the Entrepreneurial City. Eurasian Geogr. Econ. 2002, 43, 170-196. [CrossRef]

63. Akbari, H.; Shea Rose, L.; Taha, H. Analyzing the land cover of an urban environment using high-resolution orthophotos. Landsc. Urban Plan 2003, 63, 1-14. [CrossRef]

64. Cunningham, M.A. Accuracy assessment of digitized and classified land cover data for wildlife habitat. Landsc. Urban Plan 2006, 78, 217-228. [CrossRef]

65. Xiao, S.N.; Lu, Z.Z.; Xu, L.Y. Multivariate sensitivity analysis based on the direction of Eigen space through principal component analysis. Reliab. Eng. Syst. Saf. 2017, 165, 1-10. [CrossRef]

66. Vidal, R.; Ma, Y.; Sastry, S.S. Generalized Principal Component Analysis. In Interdisciplinary Applied Mathematics 40; Springer: Berkeley, CA, USA, 2016; ISBN 978-0-387-87810-2.

67. Tabachnick, B.G.; Fidell, L.S. Using Multivariate Statistics, 5th ed.; Pearson Education: Boston, MA, USA, 2007.

68. Alverti, M.; Themistocleous, K.; Kyriakidis, P.; Hadjimitsis, D. A Human Centric Approach on the Analysis of the Smart City Concept: The case of Limassol city in Cyprus. Adv. Geosci. 2018, 45, 305-320. [CrossRef]

69. Ministry of Interior, Department of Planning and Housing (2011). Limassol Structure Plan. Provisions and Policy Measures. Available online: http://www.moi.gov.cy/moi/tph/tph.nsf/page72_gr/page72_gr?OpenForm (accessed on 1 September 2019). (In Greek)

70. Pashardes, P.; Savva, C.S. Factors Affecting House Prices in Cyprus: 1988-2008. Cyprus Econ. Policy Rev. 2009, 3, 3-25. Available online: http://www.ucy.ac.cy/erc/documents/FullTextPashardesSavva.pdf (accessed on 29 March 2018).

71. Leontidou, L. Beyond the Borders of Mediterranean Cities: The Mediterranean City Transition. J. Interdiscip. Hist. 2007, 22, 131-140. 
72. Aesaert, K.; Voogt, J.; Kuiper, E.; van Braak, J. Accuracy and bias of ICT self-efficacy: An empirical study into students' over- and under estimation of their ICT competences. Comput. Hum. Behav. 2017, 75, 92-102. [CrossRef]

73. Groeneveld, R.A.; Meeden, G. Measuring skewness and kurtosis. Statistician 1984, 33, 391-399. [CrossRef]

74. Hair, J.F.; Black, W.C.; Babin, B.J.; Anderson, R.E.; Tatham, R.L. Multivariate Data Analysis, 6th ed.; Prentice Hall: Upper Saddle River, NJ, USA, 2006.

75. Harrison, A.W.; Rainer, R.K., Jr. The Influence of Individual Differences on Skill in End-User Computing. J. Manag. Inf. Syst. 1992, 9, 93-111. [CrossRef]

76. Lam, Y. Technophobia or technophilia? A preliminary look at why second language teachers do or do not use technology in their classrooms. Can. Mod. Lang. Rev. 2000, 56, 389-420. [CrossRef]

77. Abdelaziz, E.M. Exploring the Relationship between Teaching Staff' Age and Their Attitude towards Information and Communications Technologies. Int. J. Instr. 2013, 6, 215-226.

78. Scheerder, A.; Deursen, A.; van Dijk, J. Determinants of Internet skills, uses and outcomes. A systematic review of the second- and third-level digital divide. Telemat. Inform. 2017, 30, 1607-1624. [CrossRef]

79. Briguglio, M.; Formosa, G. When households go solar: Determinants of uptake of a Photovoltaic Scheme and policy insights. Energy Policy 2017, 108, 154-162. [CrossRef]

80. Kostakis, I.; Theodoropoulou, E.; Mitoula, R. Which are the determinants of recycling? A case study in Greece. Cyprus J. Sci. 2015, 13, 29-40.

81. Briguglio, M.; Delaney, L.; Wood, A. Voluntary recycling despite disincentives. Environ. Plan. Manag. 2015, 59, 1751-1774. [CrossRef]

(C) 2020 by the authors. Licensee MDPI, Basel, Switzerland. This article is an open access article distributed under the terms and conditions of the Creative Commons Attribution (CC BY) license (http://creativecommons.org/licenses/by/4.0/). 